\title{
Google en Chile: La problemática de Google Adwords analizada a la luz de la Ley de Competencia Desleal ${ }^{\mathrm{I}}$
}

\author{
Google in Chile: The problem of Google Adwords analyzed \\ through the Unfair Competition Law
}

FELIPE HERMOSILLA TORRES

Abogado, Labsen \& Cía., Chile

RESUMEN Este trabajo analiza la novedosa problemática del uso de marcas comerciales ajenas en internet como palabras clave, específicamente en el sistema de Google Adwords, a fin de determinar si dicha utilización no autorizada de signos distintivos, por parte de terceros competidores, constituye en sí mismo un acto de competencia desleal de conformidad con la Ley 20.I69. Para lo anterior, en un primer momento se examina el funcionamiento del sistema de anuncios, determinando el marco fáctico, para luego revisar los casos primitivos de jurisprudencia comparada y las soluciones de los tribunales alrededor del mundo. Finalmente, se examina un caso concreto que han conocido nuestro tribunales, observando que el fallo fue acertado en primer instancia, aunque utiliza una premisa fáctica desafortunada que no comprende cabalmente las distinciones necesarias que deben existir al tratar estas nuevas tecnologías y esta forma de publicidad.

I. Agradezco al profesor Manuel Bernet Páez, quien me introdujo en las temáticas de competencia desleal, y también a Paula Sagredo Aylwin, quien actuó como ayudante de investigación en la última etapa de este trabajo. 
PALABRAS CLAVE Internet, marcas comerciales, Google Adwords, competencia desleal, uso de marca ajena.

ABSTRACT This work analyzes the recent issue of the Internet and Law, the use of third party trademarks in advertising as keywords, specifically in the Google Adwords system, and pretends to determine if the unauthorized use of distinctive signs from competitors constitutes an act of unfair competition under the Chilean law. In this order, to answer this question, in the beginning is explained the factual framework; and then it's examined the early cases of comparative jurisprudence and court solutions around the globe. Finally, we review the case that has been known by our courts, the decision was successful in the result, but uses an unfortunate factual premise that not fully understand the distinctions that must exist to treat these new technology and this form of advertising.

KEYWORD Internet, trademarks, Google Adwords, unfair competition, use of trademarks.

\section{INTRODUCCIÓN}

El mundo ha cambiado significativamente. La tecnología ha transformado la forma en que vivimos y nos comunicamos a través de internet y las redes sociales. Estas últimas han dado lugar a nuevos negocios y tipos de publicidad, afectando intensamente las legislaciones, que de forma frecuente se aplican a nuevos escenarios del mundo moderno para los cuales no fueron concebidas.

En este contexto podemos mencionar nuevas alternativas de avisaje, dentro de las cuales una ha cobrado mayor fuerza: nos referimos al aviso que se despliega en los resultados de los motores de búsqueda, como, por ejemplo, Google Adwords. Este tipo de publicidad aparece en el navegador del computador al ingresar una palabra clave en la barra de búsqueda del buscador. En esta publicidad existe tanto un consumidor que utiliza la palabra, como un anunciante que vincula su anuncio a esa expresión o vocablo.

En virtud de estos fenómenos la normativa se ve afectada, por cuanto regulará situaciones que el legislador no tenía contempladas al momento de su redacción. No obstante, corresponde al derecho y, especialmente 
a la doctrina, resolver estas situaciones y determinar la legalidad de los nuevos tipos de publicidad, así como establecer la regulación aplicable.

En atención a lo anterior, este trabajo pretende resolver la problemática respecto de si la utilización de marcas comerciales de terceros a través de Google Adwords constituye una infracción a la luz del derecho y, particularmente, si su uso puede configurar algún ilícito de conformidad con la Ley 20.I69 que regula la competencia desleal. De tal forma, esperamos encontrar una solución concreta y pragmática.

Este trabajo se compone de dos partes. En la primera trataremos los antecedentes generales, los supuestos de hecho del avisaje que dan lugar a distintos tipos de anuncios y el funcionamiento del buscador de Google, tanto desde la perspectiva del anunciante como del usuario. Asimismo, conoceremos algunos casos de la jurisprudencia extranjera para identificar los criterios rectores que se utilizaron para resolver este conflicto.

En la segunda parte de este trabajo, luego de tener una visión general del problema a través de la revisión de casos emblemáticos que han tenido origen en internet, intentaremos dar solución al caso chileno conocido por nuestros tribunales y cuyo resultado aún se mantiene incierto. El litigio involucra a renombradas empresas nacionales de facturación electrónica, quienes demandan a South Consulting, Google Chile Ltda. y Google Inc.

Con posterioridad, determinaremos los requisitos para que un anuncio constituya una infracción a la Ley 20.I69, clasificaremos los tipos de aviso en virtud de su contenido y ubicación en el buscador, examinaremos si los signos distintivos sin registro gozan de protección y finalmente concluiremos este trabajo señalando cuál debiese ser la postura de nuestra judicatura.

\section{ANTECEDENTES GENERALES}

\section{PLANTEAMIENTO DEL PROBLEMA Y NOCIONES GENERALES}

La utilización de marcas comerciales ajenas para desplegar anuncios pagados en un sitio web es una variante novedosa de las dificultades que precedentemente habían surgido en la red.

Asimismo, corresponde señalar que a nivel mundial el conflicto traspasa las barreras de lo teórico y la cuestión ha tenido importantes re- 
percusiones, siendo conocida por tribunales germanos, franceses y norteamericanos. Sin perjuicio de que buscadores como Google operan en todo el mundo y en la medida que exista conciencia de esta tecnología y de los usos indebidos a que da origen, el problema tendrá una relevancia global y fundamental para los negocios que utilizan medios electrónicos.

Nuestro país no ha estado exento de esto, ya que ha llegado a los tribunales un caso relativo a estas materias en que una empresa de facturación electrónica llamada South Consulting Signature S.A. decidió publicar avisos publicitarios en internet con el objeto de llegar a un mayor número de clientes. Para lograr su objetivo contrató el servicio Google Adwords, el cual permite mostrar anuncios en la página del buscador del mismo nombre, previa selección de una palabra clave que se escoge libremente. Con el objeto de desplegar sus anuncios la compañía anunciante optó por los términos «Acepta», "Azurian», "DBNet» y «Paperless», pero la selección no fue al azar y se fundó en el hecho de que son signos distintivos utilizados por los usuarios que desean contratar el servicio de facturación electrónica. No obstante, la empresa que contrató el servicio no contempló que los términos utilizados son marcas comerciales de terceros competidores, que proveen exactamente el mismo servicio de facturación que los anuncios pretendían promocionar legítimamente.

De tal forma, el problema surge precisamente de la utilización de marcas comerciales de terceros para promocionar servicios propios, ya que los titulares se vieron amenazados y consideraron que existe un aprovechamiento ilícito de la reputación ajena y una desviación ilegal de clientes, lo cual pudiese encuadrarse en una infracción a la Ley de Competencia Desleal o en un uso no autorizado de una marca registrada en el Instituto Nacional de Propiedad Intelectual conforme la Ley de Propiedad Industrial (LPI).

Haciendo una breve reseña del caso, las empresas afectadas fueron: Acepta.com S.A., Azurian Tecnología Ltda., DBNET Ingeniería de Software S.A. y E-Patners S.A., lo que motivo la interposición de acciones simultáneas, fundadas en el artículo 5 de la Ley sobre Competencia Desleal y el artículo ro6 de la LPI.

Por último, cabe destacar que en el expediente consta que al ingresar en el buscador una de las marcas comerciales de los demandantes, aparece un aviso publicitario que contiene en su encabezado la marca recién 
ingresada y que el hipervínculo del anuncio redirige al usuario al sitio institucional de South Consulting S.A.

Consideramos que este tipo de prácticas no es accidental, ya que desde una perspectiva económica los agentes del mercado han percibido positivamente estos términos por ser sumamente conocidos por los consumidores. Con ellos pueden beneficiarse al disponer de anuncios asociados a estas palabras clave. Por tanto, estimamos que el caso en comento pudiese ser sólo el primero de un sinnúmero de conflictos derivados de la laxitud de la tecnología.

En los próximos años, creemos que esta práctica será bastante común, dado que los adelantos tecnológicos que lo permiten son recientes y en la medida que se masifiquen afectarán trasversalmente a las diversas industrias. Existen datos concretos que señalan que el comercio electrónico no sólo es una realidad sino que tiene una creciente importancia (Giner, 20I4).

Debido a lo anterior, es fundamental un análisis jurídico que comprenda la función que cumplen las marcas comerciales en nuestro sistema, para así delimitar claramente el derecho subjetivo del cual gozan los titulares y establecer manifiestamente los usos autorizados por el ordenamiento a terceros ajenos. En síntesis, dada la importancia práctica que goza la cuestión y por ser un tópico reciente en nuestros tribunales, merece determinarse si el mero uso de una marca ajena como palabra clave puede ser una conducta prohibida por sus respectivos titulares o, por el contrario, es de aquellos usos que escapan a su esfera de exclusividad.

\section{KEYWORD: UNA PROBLEMÁTICA DIFERENTE}

Como ya sabemos, este trabajo tratará particularmente la infracción cometida al utilizar una marca ajena en internet. No obstante, primero es necesario hacerse cargo de los usos sin autorización fuera de la red, a fin de tener claridad respecto de la regla general, y así posteriormente observar si se mantienen los mismos supuestos que fundamentan la aplicación de la regulación de forma tradicional.

Ulteriormente a ello mencionaremos sucintamente cada una de las situaciones problemáticas que se generan, con el fin de diferenciarlas de esta nueva práctica de la publicidad y así tener certeza de que estamos en presencia de una cuestión novedosa en la disciplina. 


\section{Regla general en el ámbito físico}

La legislación aplicable y relativa al uso de marcas comerciales ajenas se establece claramente en el artículo ig bis D de la LPI, al delimitar el derecho que tiene el titular sobre la marca respectiva:

La marca confiere a su titular el derecho exclusivo y excluyente de utilizarla en el tráfico económico en la forma que se le ha conferido y para distinguir los productos, servicios, establecimientos comerciales o industriales comprendidos en el registro. Por consiguiente, el titular de una marca registrada podrá impedir que cualquier tercero, sin su consentimiento, utilice en el curso de las operaciones comerciales marcas idénticas o similares para productos, servicios o establecimientos comerciales o industriales que sean idénticos o similares a aquéllos para los cuales se ha concedido el registro, y a condición de que el uso hecho por el tercero pueda inducir a error o confusión. Cuando el uso hecho por el tercero se refiera a una marca idéntica para productos, servicios o establecimientos comerciales o industriales idénticos, se presumirá que existe confusión.

De tal forma, la regla general consagrada por nuestro ordenamiento confiere un derecho de exclusividad a los titulares que han inscrito sus signos distintivos, lo que les permite prohibir el uso de sus marcas comerciales a terceros en el curso de operaciones comerciales. No obstante, esta prohibición no es absoluta, ya que se autoriza la denegación sólo en el curso de las operaciones comerciales respecto de productos, servicios o establecimientos comerciales o industriales propios, en la medida que copulativamente también haya riesgo de confusión.

Asimismo, existe una serie de usos de la marca registrada que no estarían amparados por la protección que otorga la ley, como, por ejemplo, el uso de marcas dentro de la esfera privada el cual queda fuera del ámbito de las operaciones comerciales, lo que implica necesariamente que su uso por parte de terceros es lícito.

Un ejemplo de uso lícito es la situación en que un autor utiliza las marcas que estime convenientes en la publicación de un texto derivado de las investigaciones que realiza. Inclusive en el ámbito comercial y en un caso más extremo, un tercero podría utilizar las marcas de su competencia siempre que no las utilice para diferenciar sus productos, servicios o establecimientos. Esto no ocurre con frecuencia en nuestro 
país, pero a nivel mundial en las diversas industrias se utilizan marcas de la competencia para realizar la llamada publicidad comparativa: a pesar de estar en el ámbito comercial, el tercero utiliza la marca reconociendo que le pertenecen a otro y por ello no es posible aseverar que la usa para diferenciar sus productos, servicios o establecimientos comerciales $\mathrm{o}$ industriales.

En cambio, sería ilícito utilizar la marca ajena a nombre propio puesto que se estaría utilizando la marca en el curso de operaciones comerciales y simultáneamente para distinguir productos, servicios o establecimientos, con un riesgo de confusión evidente.

Finalmente, la aplicación tradicional del derecho de marcas irroga que existen ciertos usos de los signos distintivos que están permitidos por el ordenamiento, siempre que la utilización sea en un ámbito distinto del comercial; o cuando estando en dicho ámbito, el uso no sea para diferenciar productos, servicios o establecimientos propios.

\section{Regla general en el ámbito de internet}

Al examinar la normativa aplicable y determinar que no existe regulación especial relativa al uso de marcas en internet, corresponde emplear aquella que tradicionalmente sirve para delimitar los usos de las marcas comerciales en el mundo físico. Podríamos sostener primitivamente que utilizar una marca ajena en Internet reviste entonces la misma ilicitud que tendría utilizar una marca ajena para distinguir productos y servicios propios en un periódico local.

En primer lugar, nos parece evidente que la mayoría de los nuevos negocios y un sinnúmero de las operaciones comerciales se realizan por medio de internet, siendo la difusión de la información uno de los principales propósitos de esta plataforma. Considerando estos supuestos y especialmente al develar que éste no es un ámbito privado, ya que la plataforma no considera restricciones de acceso, nos parece ineludible aseverar que internet es susceptible de considerarse una esfera de índole comercial. $^{2}$

2. Cf. la sentencia del Tribunal de Justicia de la Unión Europea del caso Google France $y$ Google (C-236/08), 23 de marzo de 20I0, apartados 50 y 5I, disponible en <http:// bit.ly/ıJoiisE>. 
En segundo lugar, al entender que internet es per se un ámbito comercial o que lo es en el caso concreto de Adwords, corresponderá determinar si el uso de las marcas como palabras clave se hace para distinguir productos, servicios o establecimientos. En principio, estimamos que utilizar la marca comercial exclusivamente como palabra clave no es un uso que esté destinado a distinguir servicios, productos o establecimientos, dado que la utilización natural de las marcas que observamos en los anuncios sólo tiene por propósito desplegar un anuncio propio, que no hace alusión a la marca ajena en su contenido.

Es importante señalar que el anuncio que sólo usa la marca ajena como palabra clave tiene un contenido visible absolutamente independiente del signo distintivo ajeno que utiliza. En este caso, el anuncio usa sus propios signos distintivos para distinguir sus respectivos productos o servicios, sin utilizar la marca ajena visiblemente. Esto será clave para entender el problema y adherir a una determinada solución, ya que al hacer la distinción será factible suponer que el mero uso de una marca ajena como palabra clave es análogo a la utilización de marcas de competidores en publicidad comparativa, lo cual ciertamente está permitido por nuestro ordenamiento.

Más adelante podremos apreciar que nuestros tribunales no distinguen el mero uso de una marca comercial como palabra clave, con el uso simultáneo de la marca como palabra clave y como parte del contenido del anuncio.

\section{Problemáticas precursoras en internet}

El uso de marcas comerciales ajenas como palabras clave no es un conflicto aislado en internet. Con el nacimiento de la plataforma han surgido diversas situaciones que entran en pugna con el ordenamiento jurídico vigente y con derechos subjetivos específicos. Por tanto, nos gustaría diferenciar la utilización de marcas comerciales ajenas contrastándola con otros hechos problemáticos que ocurren habitualmente en la red, para que sea posible observar con claridad que estamos ante un conflicto jurídico diferente.

La primera situación conflictiva que comentaremos es el linking (Hilliard, Welch y Widmaier, 2008: 455), por cuanto es una práctica sumamente común y al mismo tiempo la base de las conexiones en in- 
ternet, que consiste sucintamente en dar acceso a otro sitio web desde un sitio primitivo a través de un hipervínculo, lo cual ha sido considerado como una conducta que no reviste conflicto (Hilliard, Welch y Widmaier, 2008). No obstante, estas posibilidades derivadas del avance tecnológico han generado ciertos problemas cuando un sitio web utiliza un dominio que pudiese aludir a la propiedad industrial de otra empresa.

En Estados Unidos, la compañía de automóviles Nissan intentó limitar el contenido que podía publicar la compañía Nissan Computers, cuyo dominio es <http://www.nissan.com>. Esta última se dedicaba al rubro de la computación y su uso se amparaba plenamente en que el apellido del dueño coincidía con la famosa automotora. Sin éxito y en una etapa bastante primitiva de internet, se quiso delimitar el contenido y publicidad del sitio, pero no había una vulneración a los derechos de los demandados, ${ }^{3}$ o no podía entenderse como vulneración la utilización legítima de derechos propios.

Igualmente existe la posibilidad de enlace profundo o deep linking, que consiste en utilizar un hipervínculo para llevar al usuario a una página de un sitio web ajeno que está varios niveles debajo de su respectiva página principal (Hilliard, Welch y Widmaier, 2008). Esta situación ha sido considerada problemática, dado que este enlace profundo que redirige al usuario afecta de forma relevante a los propietarios de la página cuyo material se utiliza. En particular, reduce el tiempo que el usuario está en el sitio, además de ser una forma de ignorar las condiciones de uso y los anuncios de la web cuyo contenido se extrae, hecho ciertamente relevante y que en ocasiones puede ser parte del modelo de negocio de la empresa (Hilliard, Welch y Widmaier, 2008).

Las posibilidades técnicas y materiales que provee internet son variadas. Así como existe la posibilidad de enlazar el contenido de diversos sitios web mediante un hipervínculo, también es posible abrir directamente contenido de un sitio web ajeno en el propio. En palabras simples, es posible que nuestro sitio web incluya dentro de su propia estructura una «ventana» en la que simultáneamente se muestra el contenido de una página web ajena. Esto se conoce como framing (Hilliard, Welch y Widmaier, 2008) y ciertamente reviste un conflicto

3. Nissan Motor Co. v. Nissan Computer Corp., 378 F.3d I002, I020 (9th Cir. 2004). 
manifiesto al constituir la utilización de obras protegidas por el derecho de autor. ${ }^{4}$

Asimismo, existen figuras más modernas del framing, como barras superiores o laterales, que podemos apreciar muchas veces al navegar en la red. Similar problemática ocurre con el servicio de Google News, ${ }^{5}$ el que capta usuarios utilizando noticias confeccionadas por terceros, lo que pudiese estar vulnerando eventualmente los respectivos derechos de sus autores. Por último, cabe mencionar que Google Adsense es un sistema de publicidad que utiliza esta misma técnica, permitiendo que los usuarios ganen dinero al insertar anuncios gráficos en sus propios sitios en línea, siendo parte del contenido del mismo.

También ha sido frecuente encontrar referencias sobre los metatags: éstos son parte de los parámetros ocultos que contiene una página web en su código fuente. Materialmente consisten en palabras que se ingresan en dicho código y que hacen alusión a los tópicos más representativos del sitio. Sirven a los motores de búsqueda como factor para dar prioridad a un sitio por sobre otro en la lista de resultados que ve el usuario, mejorando su ubicación en los resultados naturales. De tal forma, el problema radica en que se han utilizado para desviar a los consumidores sin discriminar si el término utilizado corresponde a una marca comercial, lo que ha generado confusión en los usuarios que, buscando una página específica, han sido derivados, por ejemplo, a sitios de la competencia. También podrían creer que existe una vinculación económica entre la marca que ingresaron en el buscador y el sitio que finalmente visitan (Hilliard, Welch y Widmaier, 2008).

\section{MOTORES DE BÚSQUEDA}

Como ya lo adelantábamos, la publicidad a través de palabras clave es uno de los nuevos casos de conflicto jurídico en internet. Con el propó-

4. Por medio de la técnica relatada, es factible reproducir, en una página web propia, fragmentos o derechamente obras ajenas íntegras que están amparadas por la Ley I7.336, como libros, folletos, artículos, fotografías, etcétera. Inclusive, una página web es en sí misma una creación intelectual resguardada por el derecho de autor.

5. En el sitio web <https://news.google.cl/> puede observarse cómo Google utiliza contenido de terceros prácticamente en tiempo real, indexando diversas noticias de medios de comunicación del mundo. 
sito de entender a cabalidad los presupuestos y los supuestos fácticos que operan en esta práctica, lo primero que haremos será referirnos a los motores de búsqueda, que son indispensables para entender en qué consiste el uso de una marca ajena como palabra clave.

Desde la aparición de internet hemos podido apreciar el nacimiento de distintos servicios en línea. Los buscadores se han convertido en un cimiento de la navegación en la red, siendo una herramienta de utilidad pública y un medio muy atractivo para la publicidad (Jacoby y Sableman, 2007).

Los motores de búsqueda son sistemas de indexación de internet, que despliegan la información en una lista de resultados en virtud de la palabra clave que ingresó el usuario en la «barra de búsqueda». ${ }^{6}$ Una palabra clave es el término que ingresa el cibernauta en la barra de búsqueda con el fin de obtener una lista de resultados naturales ${ }^{7} \mathrm{O}$ "resultados de búsqueda». ${ }^{8} \mathrm{El}$ servicio indexa y ordena los resultados acorde a criterios objetivos de relevancia establecidos por el mismo sitio. Algunos de los parámetros que utiliza son el tráfico de la página (la cantidad de visitas), la coincidencia entre la palabra clave y el contenido del sitio, su descripción y su título.

Por último, cabe destacar que la coincidencia entre la palabra clave que ingresó el usuario y los resultados que despliega el buscador no siempre será literal. Como mencionamos anteriormente, una página web posee elementos ocultos que ayudan a mejorar la indexación por parte de los buscadores, por lo que podría aparecer un sitio en los resultados con el que aparentemente no hay coincidencias.

Al describir con mayor detalle la lista de resultados de búsqueda de Google encontramos que cada uno de los resultados que aparece en el

6. Google, «Página de resultados de búsqueda de Google», disponible en <http://bit. ly/IfowgDg>.

7. Existe cierta uniformidad al referirse al contenido que aparece luego de ingresar una palabra clave como resultados naturales, expresión que hace alusión a que los criterios utilizados para desplegar los resultados son objetivos y no existe una intervención de parte de la empresa, más allá de fijar los criterios predeterminados para que un sitio tenga preponderancia sobre otro.

8. Google, «Página de resultados de búsqueda de Google», disponible en <http://bit. ly/1f0w9Dg>. 
buscador contiene un encabezado, un fragmento y la URL. ${ }^{9}$ El encabezado es el título de la página web, que no es elegido por Google, sino por el dueño del sitio web. El fragmento es una breve descripción del sitio que también es elegido por el creador, y finalmente la URL o dirección corresponde al dominio que se utiliza para enlazar el contenido alojado en un servidor a un nombre o término específico.

Google Adwords $^{\text {Io }}$ permite a sus clientes alterar los «resultados naturales» ${ }^{\mathrm{II}}$ al introducir anuncios $\mathrm{O}$ "enlaces patrocinados». ${ }^{\mathrm{I2}}$ En la figura I se pueden apreciar dos enlaces de resultados naturales en conjunto con los enlaces patrocinados, estos últimos pueden aparecer en el centro de la parte superior, inferior y/o en el extremo derecho de la pantalla.

Personalmente, durante el año 2012 realizamos el ejercicio de abrir el navegador, ingresar al sitio web de Google y escribir en la barra de búsqueda las palabras clave «magos en Chile». Automáticamente se desplegó la lista con los resultados más relevantes como ya pudimos apreciar en la figura I, además se observa en la imagen el formato común ya descrito precedentemente. También podemos ver los anuncios en la parte superior, distinguiéndose a través del color del fondo.

$\mathrm{Al}$ acceder durante el año $20 \mathrm{I} 5$ e ingresar la palabra clave «abogado infraestructura», pudimos observar lo que muestra la figura 2, mostrando el dinamismo con el que se modifican los anuncios, que han sufrido cambios sustantivos durante los últimos años respecto de su presentación gráfica.

\section{GOOGLE ADWORDS: UN SISTEMA DE ANUNCIOS}

Google Adwords consiste en un sistema de publicidad mediante palabras clave, donde los usuarios del servicio eligen libremente la palabra que prefieren para que su anuncio se despliegue. Ésta no tiene que tener necesariamente una coincidencia con el aviso que se pretende publicar,

9. La sigla responde a la expresión inglesa uniform resource locator.

ı. Google, «How keyword work», disponible en <http://bit.ly/1M8YLs2>.

I I. Cf. la sentencia del Tribunal de Justicia de la Unión Europea (TJUE) del caso Google France y Google (C-236/08). En ella se utiliza la nomenclatura de resultados naturales con el objeto de diferenciarlos de los anuncios que se superponen al orden previamente establecido conforme criterio fijos determinados por el buscador.

I2. Véase TJUE, Google France y Google (C-236/o8). 


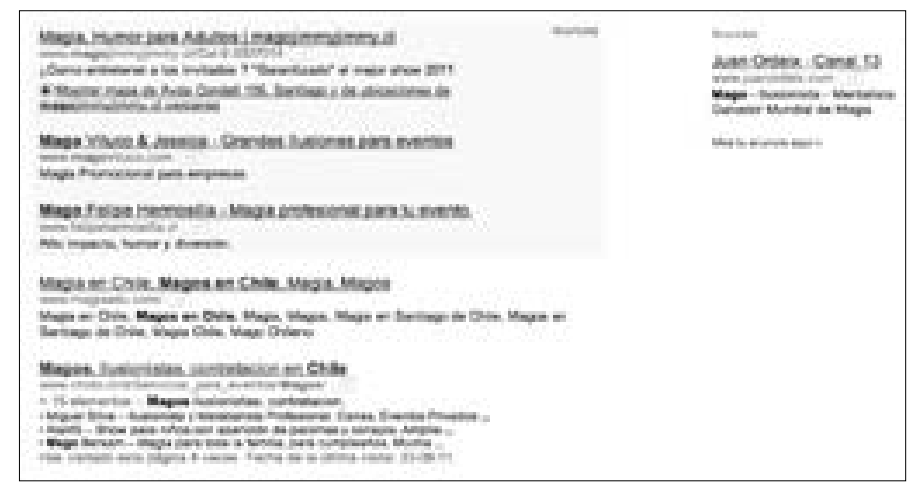

Figura 1.

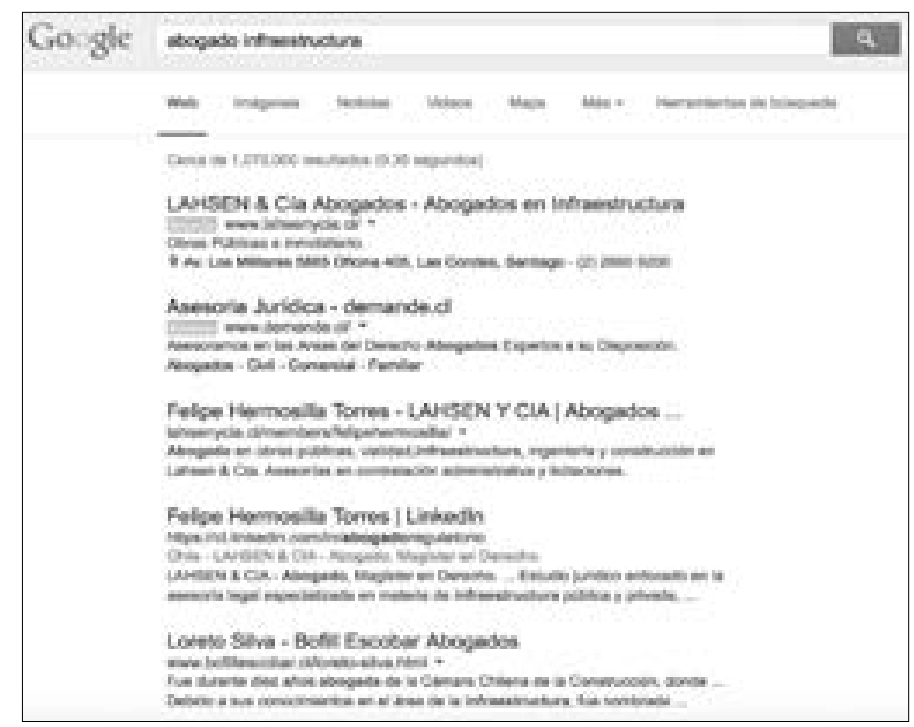

Figura 2.

de hecho hay completa libertad en este aspecto al no exigir ningún tipo de relación de contenido entre la palabra clave y el anuncio. El funcionamiento del despliegue es una cuestión exclusivamente formal, es decir, que el anuncio aparece ante el cibernauta en virtud de los términos que previamente ha seleccionado el usuario del servicio. ${ }^{13}$

Ahora nos referiremos a los pasos necesarios que debe seguir una empresa o un particular para publicar un aviso e inscribir las respectivas palabras clave que harán que el anuncio aparezca. Para estos efectos,

I3. Google, «Google AdWords: An overview for advertisers», disponible en <http:// bit.ly/1fGuKTc>. 
hemos completado el formulario que entrega Google para configurar los atributos del aviso, mostrando así de forma más didáctica cómo se inscribe y a qué corresponde cada parámetro (figura 3 ).

En la misma figura, estamos en presencia del panel de administración al cual tienen acceso los usuarios del servicio de publicidad. En la sección anuncios que corresponde al módulo en el cual se escoge y determina el contenido del aviso. En el formulario que aparece en la parte inferior de la figura 3 podemos observar los diversos parámetros señalados previamente en este trabajo y los que cada anunciante determina con su propio contenido.

\section{FUNCIONAMIENTO DE GOOGLE ADWORDS}

Para tener una mejor concepción acerca del sistema explicaremos cómo funciona el servicio proporcionado por Google. En primer lugar, el usuario debe registrarse para tener una cuenta en el sistema. Posteriormente debe crear una «campaña» que corresponde a la denominación que recibe el conjunto compuesto por palabras clave, anuncio y normas de facturación. El nombre de la campaña sólo tiene relevancia formal e interna para efectos de identificar el anuncio asociado a determinadas palabras clave. Una vez creada la campaña el usuario debe escoger el anuncio y la página web a la que pretende dar publicidad.

En la pestaña «anuncio» podemos apreciar el encabezado, la descripción y el enlace al sitio web, al igual que en los resultados naturales. Al haber determinado el anuncio se debe escoger entre dos sistemas para establecer el modo de cobro mediante el cual se regirá el aviso. El primero cobra por impresiones, lo cual significa que el costo final dependerá de las veces que los usuarios vieron el anuncio desplegado en su pantalla. Mientras que el segundo se rige por clics, lo que implica que el anunciante pagará a Google cada vez que potenciales clientes hayan ingresado efectivamente a su sitio web desde el aviso publicitario.

La figura 4 muestra una impresión de pantalla en la cual vemos una campaña creada y la facilidad con la que podemos agregar palabras claves a un anuncio al hacer clic en el botón «Añadir palabra clave». Verificamos que no existe ningún tipo de restricción por parte de Google al momento de escoger palabras clave. Además es importante recalcar que no se restringe el contenido ni el número de keywords utilizadas. 


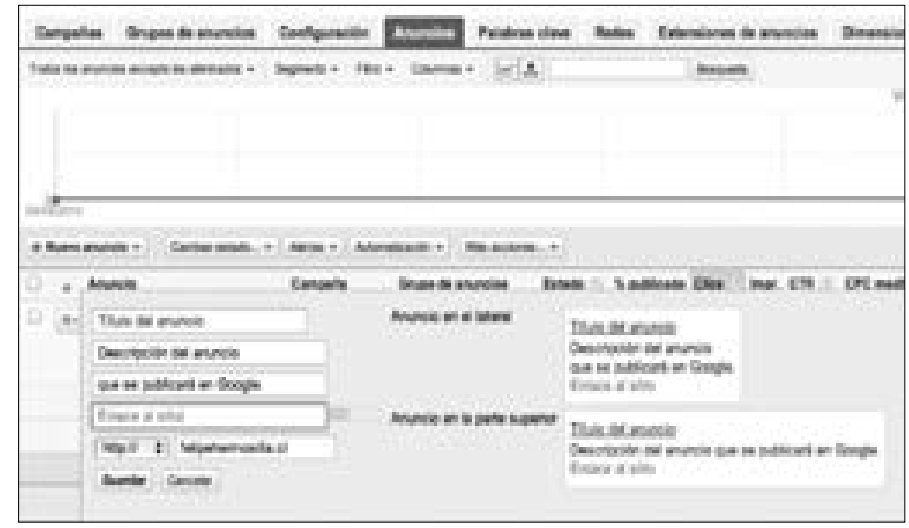

Figura 3.

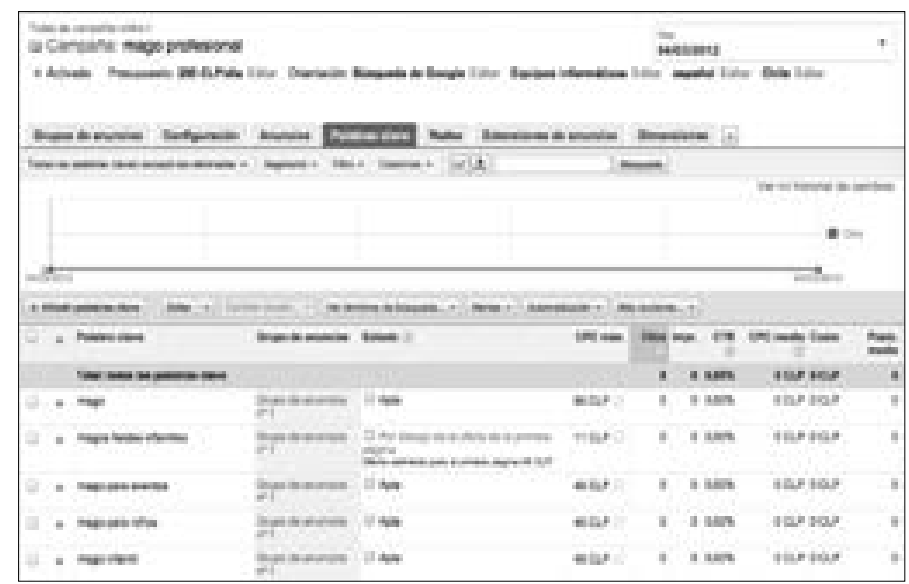

Figura 4.

A través de lo expuesto, hemos constatado que la problemática surge precisamente de la posibilidad que otorga el sistema al anunciante de elegir libremente marcas comerciales o signos distintivos como palabras clave, sin tener la obligación de acreditar la titularidad o la relación con el signo en cuestión. Nos parece desafortunado que, al momento de probar el sistema, sea posible establecer una dirección web visible que no coincida con la dirección a la que el usuario es redirigido efectivamente, pudiendo dar lugar a diversos escenarios de confusión que podrían constituir infracciones marcarias o desleales.

A continuación revisaremos algunos de los casos emblemáticos en búsqueda de las soluciones que ha dado la jurisprudencia alrededor del mundo. 


\section{JURISPRUDENCIA COMPARADA}

INSERTANDO EL TEMA EN UNA DISCIPLINA

A continuación, trataremos la jurisprudencia que ha aportado significativamente a dilucidar la cuestión desde una perspectiva jurídica, que contempla el derecho de los titulares y las limitaciones de la publicidad en internet, con el objeto de tener mayores antecedentes para tratar el caso chileno y dar una respuesta integral conforme a nuestro derecho.

Cabe destacar que estas discusiones se han planteado en el ámbito del derecho marcario, debido a la pugna entre el derecho que gozan los titulares de las marcas comerciales para distinguir sus productos, servicios o establecimientos de comercio, con la situación de facto en que los anunciantes utilizan dichos signos protegidos como palabras clave para desplegar sus avisos publicitarios. Por otro lado, también se ha esgrimido el régimen de la competencia desleal como el conjunto de reglas aplicable a esta materia. Se sostiene que los anuncios en internet y en particular los que utilizan marcas ajenas como palabra clave, generan confusión en los consumidores. Esto se debe a que los cibernautas no pueden establecer con claridad si la página web que visitan corresponde al titular de la marca o si por el contrario pertenece a un competidor.

\section{JURISPRUDENCIA NORTEAMERICANA}

A continuación trataremos algunos de los casos de publicidad a través de palabras clave que han tenido lugar en Estados Unidos, con el propósito de tener una visión más amplia de los razonamientos, supuestos fácticos y conclusiones respecto de este tipo de avisaje.

La jurisprudencia norteamericana es la más fructuosa debido a que la gran mayoría de casos existentes han tenido lugar en sus tribunales, gozando de una cantidad y variedad muy superior al compararla con otros países.

\section{Casos referenciales}

En un primer momento nos referiremos a algunos de los casos que anteceden al problema generado por el sistema de publicación de anuncios 
de Google. Estos fueron citados en los juicios de Adwords y además han sido utilizados por la doctrina extranjera como juicios precursores.

Playboy versus Netscape. No hay mejor ejemplo que el primer caso que se conoce en Estados Unidos, Playboy Enterprises, Inc. v. Netscape Communications (Jacoby y Sableman, 2007). Mientras que la primera es una conocida empresa de entretenimiento para adultos, la segunda es una empresa de comunicaciones que tuvo entre sus primeros productos un buscador similar al de Google.

Con lo anterior queremos reforzar nuestra propia apreciación acerca del caso, ya que como pudimos constatar en esta sentencia, éste es sin duda el primer juicio que denota la importancia y el conflicto que genera utilizar marcas comerciales renombradas como palabra clave.

Con el objeto de tener nuestra propia opinión acerca del caso, haremos un sumario de los hechos descritos en la sentencia de la Corte de Apelaciones del Noveno Circuito. En palabras de la Corte: «Este caso implica una práctica llamada keying que los demandados usan en sus motores de búsqueda de internet. Keyings permite a los anunciantes apuntar a individuos con cierto interés al vincular anuncios a términos predeterminados», ${ }^{\mathrm{I}}$ lo cual consideramos una primera alusión a lo que actualmente se conoce como keyword advertising.

$\mathrm{Al}$ interiorizarnos en el caso, se señala en los hechos que los términos que se utilizaron y generaron la contienda son «Playboy» $\mathrm{y}$ «Playmate». ${ }^{15}$ Cuando el usuario los ingresaba en el motor de búsqueda, un anuncio de la categoría entretenimiento para adultos aparecía en la pantalla. Playboy Enterprises International Inc. alegó una infracción a la protección otorgada por la marca registrada amparado en la doctrina de la dilución. ${ }^{\mathrm{I}}$

En primera instancia se sostuvo, por parte de los demandados, que los usos de los referidos términos no se hacían en su calidad de signos

I4. Playboy $v$. Netscape, 354 F.3d I020 (9th Cir. 200I). La traducción es nuestra.

I 5. Playboy v. Netscape, 354 F.3d IO20 (9th Cir. 200I).

I6. La teoría tuvo su origen en Estados Unidos y se utiliza como justificación para prohibir diversos usos marcarios de marcas renombradas. Esta doctrina sostiene que incluso el uso de una marca renombrada fuera del ámbito de exclusividad, provoca un menoscabo en la función de calidad de la misma, debido a que ésta comenzaría a asociarse con otros signos distintivos de menor prestigio (Barret, 2006). 
distintivos registrados, ya que éstos tienen un significado propio en el idioma. De tal forma, por el hecho de ser palabras de uso común, no sería comparable utilizar la palabra «playboy» como término de búsqueda a utilizarla como marca registrada (Lastowka, 2008). También se argumentó que dictar una sentencia contra Netscape era permitir el monopolio de la palabra "playboy», fallando en contra de la primera enmienda y por ende violando los derechos de los demandados.

En un primer momento el tribunal del distrito no acogió la demanda, debido a que en virtud del razonamiento expuesto por la parte demandada no era posible sostener que el uso de las palabras señaladas constituyeran a su vez el uso de una marca registrada (Lastowka, 2008).

La Corte de Apelaciones del Noveno Circuito de Estados Unidos reconsideró la decisión de primera instancia para resolver el conflicto con el objeto de establecer si existía una probabilidad de confusión, ponderando los mismos factores que fueron utilizados anteriormente por el tribunal primitivo. Con el propósito de otorgar más parámetros y directrices al tratar el caso en Chile, enumeramos los criterios más relevantes examinados por el tribunal de alzada:

- Fuerza de la marca. Esto se refiere básicamente a la capacidad distintiva de la marca. En el presente caso los términos utilizados llegaron a adquirir un significado secundario, distinto de la palabra en el propio idioma.

- Proximidad de los servicios. La Corte señaló que los servicios son los hipervínculos y los productos de los sitios web a los cuales redirigían los anuncios. Por lo comentado, estamos en presencia de productos prácticamente idénticos, ya que ambas páginas ofrecían entretenimiento para adultos.

- Similitud de las marcas. Respecto de este punto, el tribunal dio por acreditado que se estaba en presencia de marcas idénticas, ya que se utilizó la forma plural de «playmate».

- Evidencia efectiva de confusión. Entre los antecedentes, se contó con un estudio que sostenía que el 5 I \% de los participantes creía que los anuncios eran patrocinados por Playboy o que existía una asociación entre la empresa del anuncio y la marca que ingresaron.

- Tipo de servicio y el grado de importancia que le asigne el com- 
prador. Se sostuvo que al tratarse de productos de bajo costo, el cuidado del consumidor también sería menor. De tal forma, el tipo de producto favorece que exista confusión entre los usuarios del navegador, ya que no tienen la atención necesaria para poder distinguir entre un proveedor y otro.

- Intención del infractor de seleccionar la marca y generar confusión. A pesar de ser un elemento relevante para determinar si existe probabilidad de confusión, la Corte estableció que no se aprecia una intencionalidad de parte de la empresa anunciante, agregando que tampoco hacían algo por evitarla.

Conforme a lo señalado, la Corte del Noveno Circuito consideró que existió dilución al utilizar signos distintivos que son iguales a las marcas protegidas de los demandantes, y por ende dio por acreditada la infracción marcaria.

Debemos destacar que fue evidente para la Corte que al ingresar la palabra clave lo que buscaban los usuarios realmente era el contenido que se le atribuye a las marcas comerciales y en ningún caso el significado que tienen los términos en el idioma. Se acogió la demanda y se revocó la sentencia de primera instancia, en virtud del riesgo de confusión que se generaba a raíz de este tipo de anuncios. ${ }^{17}$

Brookfield Communications, Inc. $v$. West Coast Entertainment Corp. Si bien este caso no es indispensable para tratar el keyword advertising, sin duda es un litigio que ha aportado significativamente a la disciplina y que merece observarse, con la intención de obtener una visión más amplia en relación con el uso de marcas ajenas como palabras clave en internet.

En cuanto a los hechos, la empresa Brookfield es titular de la marca comercial Moviebuff, e intentó registrar el dominio con el mismo nombre, percatándose que otra compañía denominada West Coast ya lo tenía asignado. De tal forma, Brookfield se vio obligada a registrar el dominio moviebuffonline.com para poder lanzar su sitio que contaba con una base de datos de información sobre la industria del cine y que pretendía en un principio utilizar la marca registrada de la cual es titular.

17. Playboy v. Netscape, 354 F.3d 1020 (9th Cir. 2001). 
El conflicto surge cuando West Coast lanza un sitio web utilizando el dominio que previamente había registrado y que coincidía con la marca registrada de Brookfield. La pugna radica en determinar la primacía entre el derecho de marcas y los derechos sobre un nombre de dominio que coinciden completamente. Por otro lado, cabe destacar que paralelamente se discute el conflicto que genera el parecido entre el contenido de ambos sitios.

En paralelo, se discutió si es admisible a la luz del derecho la utilización de marcas ajenas como metatags (etiquetas o términos invisibles al usuario), que influyen en la relevancia y prioridad que tendrá el sitio en los resultados de búsqueda. Cabe destacar que éste es el primer caso de metatags del que se tiene registro. En él se observa su mal uso dado que las etiquetas consistían en marcas comerciales de un tercero competidor, provocando con ello la consiguiente desviación de clientes.

En lo sustantivo del fallo, se utilizó como parte de los fundamentos la teoría del interés inicial, la cual queda bastante clara al presentar el siguiente ejemplo: en una autopista un conductor es desviado de su camino por un letrero ambiguo y en vez de llegar al establecimiento comercial deseado llega a un local de la competencia. Si bien el conductor no está confundido cuando finalmente entra al establecimiento comercial, en principio es desviado por la confusión que le provoca el anuncio (Jacoby y Sableman, 2007). Más grosero sería el caso en que se utilice derechamente la marca de la competencia para desviar al conductor, que finalmente podría contratar en el local de la competencia porque ha sido desviado y su tiempo es escaso.

Además de lo ya señalado, la Corte no acogió el argumento de los demandantes, que sostenía que utilizaban el término meramente de forma descriptiva, ya que al igual que en el caso de Playboy que se cita en la sentencia, la marca se utilizaba por la fuerza de la misma y su notoriedad en el mercado.

Este caso es particularmente importante porque podría ser utilizado como analogía por los dueños de marcas registradas para cuestionar su uso en dominios de páginas web, metatags o en palabras clave, ya que aunque se sostenga que no existe un uso comercial de la marca, igualmente se generaría confusión, incluso en el caso de que ésta se disipe al momento de la compra, ya que indistintamente desvía clientes aprovechándose de la reputación ajena (Jacoby y Sableman, 2007). 
Finalmente, la Corte del Noveno Circuito concluyó que los derechos que tienen los titulares sobre un dominio web no predominan sobre una marca registrada. Afirmando que cuando un competidor utiliza una marca ajena como nombre para su sitio web, los usuarios probablemente se confunden, al igual como lo hacen cuando ingresa una marca comercial al buscador y son desviados por los metatags a un sitio web no relacionado.

Ulteriormente, la Corte aseveró que estas situaciones son precisamente las que el derecho de marcas se encarga de evitar. ${ }^{18}$ Por otro lado, sin que los nombres de dominio representen un aspecto esencial del trabajo, sin duda es relevante destacar que en la actualidad las disputas en esta materia se resuelven de conformidad con la Política de Resolución de Conflictos de Nombres de Dominio (Uniform Domain-Name DisputeResolution Policy, UDRP) instaurado por The Internet Corporation for Assigned Names and Numbers (ICCAN).

\section{Google Adwords}

A continuación trataremos casos concretos que involucran al sistema de Adwords. Estos casos se dieron en Estados Unidos y tratan el conflicto que surge entre los titulares de las marcas y los anunciantes que las utilizan como palabra clave.

Geico versus Google. Government Employees Insurance Co. es una conocida compañía aseguradora presente en Estados Unidos, que ofrece pólizas de seguro para vehículos motorizados. Esta empresa demandó a Google por su sistema de publicidad basado en palabras clave, en virtud de los siguientes fundamentos. ${ }^{19}$

Geico alegó en su demanda infracción marcaria directa e indirecta, infracción marcaria contributiva por permitir que un tercero infringiera los derechos, representación falsa y dilución bajo la Lanham Act. Siendo esta última una de las transgresiones más relevantes, ya que sus presupuestos podrían utilizarse para justificar la prohibición de uso como palabra clave en la legislación chilena. Todo lo anterior, derivado de

I8. Brookfield v. West Coast ENTMT, I74 F.3d I036 (9th Cir. I999).

I9. Geico v. Google, 330F. Supp. 2d 700 (2004). 
la probabilidad de que los consumidores que utilizan su marca como palabra clave en el sitio web de Google se confundieran y creyeran que existe una relación entre los anunciantes de los enlaces patrocinados y la empresa titular, u otra situación similar. Por su parte, el motor de búsqueda negó la violación del derecho marcario dejando recaer el peso de la prueba sobre el demandante y sosteniendo que el uso de las marcas comerciales a través de su sistema es un uso interno y por ende no comercial.

Cabe destacar que conforme a la Lanham Act $^{20}$ el demandante debe probar lo siguiente: que posee la marca, que el demandado usó dicho signo, que la usanza ocurrió en un contexto comercial, en relación con ventas, distribución o publicidad de productos o servicios, y finalmente que el demandado utilizó la marca de una manera en que sea probable confundir a los usuarios. Cuestiones que mayoritariamente se dan por acreditadas, ya que la Corte entiende que el uso es comercial a pesar de lo señalado por los demandados. No obstante, señala que ello no implica necesariamente una infracción marcaria o una contravención al common law de Virginia, ya que debe determinarse si el uso es legítimo o no, así como también corresponde establecer fehacientemente si genera confusión en los usuarios.

Finalmente, la Corte del Distrito de Virginia consideró, en relación con las reclamaciones fundadas en la Lanham Act, que los demandantes no tuvieron éxito en acreditar que existió un riesgo de confusión derivado del uso de la marca, dado que no se aportó con pruebas suficientes, ni se hacía referencia a la marca en el encabezado, siendo el contenido del anuncio insuficiente para producir confusión conforme la ley federal de marcas o al common law de Virginia (Jacoby y Sableman, 2007).

Rescuecom versus Google. Rescuecom es una compañía que repara computadores y conduce la mayoría de sus negocios a través de internet (Sharples, 2009). Esta empresa acudió a los tribunales estadounidenses al constatar que sus marcas comerciales eran sugeridas a través de la herramienta del sistema de publicidad de Google denominado «Keyword

20. Normativa federal norteamericana que establece un sistema nacional de registro y protección de los titulares de marcas comerciales, la cual prohíbe expresamente entre otras conductas la dilución marcaria. 
Suggestion Tool». ${ }^{21}$ En primera instancia, la Corte del Distrito de Nueva York desechó la demanda entablada por la empresa al considerar que dicho uso no es comercial, por cuanto éstas no se exhiben en el comercio.

Este caso es relevante porque se aleja del paradigma clásico en el que se entiende que Google y los motores de búsqueda son simplemente una herramienta automatizada. Habitualmente entendemos que los proveedores de contenido no tienen responsabilidad en la medida que dispongan de los procedimientos adecuados para denunciar infracciones, pero aquí vemos una participación activa por parte del buscador que recomienda expresamente marcas comerciales que tienen un nivel de tráfico relevante. ${ }^{22}$

Continuando con el caso, Rescuecom demandó a Google en primera instancia por infracción de marca registrada, falsa designación de origen y dilución, bajo la Ley Federal de Marcas, artículos I 5, I I I 4 y i 25. Rescuecom alegó que Google por medio de sus recomendaciones, y en particular a través de un anuncio de la competencia, generaba confusión en los consumidores.

La utilización de su marca comercial permitía engañar y desviar a sus clientes, dado que el anuncio podía entenderse como parte de los resultados de búsqueda más relevantes. Precisamente, porque el anuncio aparecía en primer lugar por sobre los resultados naturales en la parte superior de la lista e imitando el mismo formato.

La Corte de Apelaciones del Segundo Circuito básicamente reexaminó el antiguo precedente que sostiene que el uso de una marca comercial en el directorio interno de un computador no constituía un uso en comercio, ya que anteriormente el tribunal primitivo no lo trató apropiadamente. Cabe destacar que dicho razonamiento tiene sentido cuando

2I. Rescuecom Corp. v. Google Inc., 562 F.3d I 23 (2nd Cir. 2009).

22. Ciertamente, la responsabilidad de Google es un tema que se seguirá discutiendo, pero queremos destacar que existen fundamentos para imputarle algún tipo de responsabilidad. Por ejemplo, actualmente no es posible irrogar responsabilidad a Youtube por los contenidos que vulneran la propiedad intelectual, ya que entendemos que el proveedor es un mero intermediario. No obstante, los supuestos y las conclusiones cambian radicalmente si el distribuidor de videos incitara activamente a subir cierto contenido infractor. Esto último lo comentamos para ilustrar el caso de Google, en que los anunciantes eligen libremente palabras clave en un contexto en el cual el proveedor recomienda marcas activamente. 
el uso es estrictamente interno y no es comunicado al público. Sin embargo, en los hechos se pudo constatar que la marca se sugiere en una plataforma exclusiva de clientes, para posteriormente ser publicada en anuncios masivos. En virtud de lo expuesto, la Corte concluyó que el uso de marcas comerciales como palabras clave constituye un uso comercial, sin perjuicio de que debe probarse la probabilidad de confusión conforme a la Lanham Act.

\section{Recapitulación}

De acuerdo a lo visto, existen principalmente dos líneas argumentativas. En primer lugar, la visión de los titulares de marcas comerciales que velan por su derecho de exclusividad. En segundo lugar, la postura de los anunciantes de Adwords, que ven en este tipo de publicidad una forma legítima de competir a través de internet.

En Playboy $v$. Netscape surge un argumento que busca limitar la extensión del derecho de marcas, al entender que las marcas comerciales no pueden monopolizar el lenguaje, amparándose en el derecho a la libertad de expresión.

Es pertinente mencionar que dicho razonamiento se ajusta a la tesis restrictiva sobre el derecho de marcas que entiende que «el titular sólo puede prohibir a los terceros el uso de un signo idéntico o confundible que se efectué a título de marca» (Fernández-Novoa, 2004: 438). No obstante, en este caso en particular los usuarios utilizaban los términos en el sentido que se le atribuye a la marca comercial.

En el examen del primer caso sobre metatags del cual se tiene registro en Estados Unidos constatamos que la confusión inicial que se disipa al momento de la compra igualmente causa un perjuicio al titular de la marca por la desviación de clientes. Además, es factible homologar esta situación a la confusión que pueden experimentar los consumidores que utilizaron una marca como palabra clave y fueron desviados por un anuncio que aparece en los primeros resultados del buscador.

También tratamos los primeros casos norteamericanos de Adwords, en los cuales se aprecia el paradigma tradicional de conflicto entre titulares y anunciantes e intermediarios, en el cual los primeros pretenden prohibir la utilización de sus marcas fundados en que el anuncio genera confusión en los usuarios. Mientras que los demandados sostienen 
que no existe una infracción puesto que no se configura un uso marcario propiamente tal. En tanto Google alega ser un mero intermedio que no tiene responsabilidad por las palabras clave que seleccionen sus usuarios.

En Rescuecom v. Google se cuestiona el rol pasivo del buscador como intermediario, dado que su sistema de publicidad contiene un software que realiza sugerencias de palabras clave que incluye marcas comerciales.

\section{GOOGLE FRANCE EN EL TRIBUNAL DE JUSTICIA DE LA UNIÓN EUROPEA}

Como mencionábamos, el uso no autorizado de marcas como palabras clave es una problemática mundial y los tribunales franceses debieron resolver diversos casos que involucran a Google. A continuación, mencionaremos cómo llegó a conocer del asunto el Tribunal de Justicia de la Unión Europea y además señalaremos los más grandes aportes de esta jurisprudencia con miras a resolver la problemática en nuestro país.

En relación con tres casos conocidos por la judicatura francesa que tratan el uso de marcas ajenas como palabra clave, se remitió una petición de decisión prejudicial con el objeto de que el Tribunal de las comunidades interpretará un conjunto de disposiciones comunitarias. ${ }^{23}$

\section{El concepto de uso marcario}

Haremos una breve reseña de los casos C-236/08, C-237/08 y C-238/08 con la intención de aclarar el contexto y posteriormente señalaremos qué entiende la jurisprudencia de este tribunal por uso marcario.

El primer caso trata sobre una empresa dedicada al comercio de bolsos de lujo, titular de la marca comunitaria Vuitton y de las marcas Louis Vuitton y LV en Francia. Los titulares de la marca comprobaron

23. El artículo 5, apartados I y 2, de la Directiva 89/I04/CEE del Consejo, del 2 I de diciembre de 1988; la Primera Directiva relativa a la aproximación de las legislaciones de los Estados miembros en materia de marcas (DO I989, L 40, p. I); artículo 9, apartado I, del Reglamento (CE) 40/94 del Consejo, de 20 de diciembre de I993, sobre la marca comunitaria (DO I994, L I I, p. I); y artículo I 4 de la Directiva 2000/3 I/CE del Parlamento Europeo y del Consejo, de 8 de junio de 2000, relativa a determinados aspectos jurídicos de los servicios de la sociedad de la información, en particular el comercio electrónico en el mercado interior (Directiva sobre el comercio electrónico) (DO L I78, p. I). 
en el año 2003 que al ingresar la palabra clave «Vuitton» al motor de búsqueda, se podía apreciar en los resultados enlaces que redirigían a sitios en los que se vendían imitaciones de la marca. Además, no sólo era posible seleccionar las marcas como palabras clave, sino además combinarlas con las palabras «imitación» o «copia».

En virtud de los hechos relatados, la compañía Vuitton procedió a demandar a Google por violación de sus derechos de marca. Finalmente, tras agotar las acciones jurisdiccionales y en medio de un proceso de casación, la Corte de Casación de Francia suspendió el procedimiento a la espera de que el Tribunal de Justicia de la Unión Europea (TJUE) se pronunciara sobre la petición prejudicial. ${ }^{24}$

El segundo litigio involucra a Viaticum, que es titular de las marcas francesas Bourse des Vols, Bourse des Voyages y BDV. Todas fueron registradas para servicios de organización de viajes, rubro en el cual se desempeña el demandante. ${ }^{25}$ Además Luteciel, empresa dedicada a la prestación de servicios informáticos para agencias de viajes, se dedica a la edición y mantenimiento del sitio de internet de Viaticum.

Ambas empresas pudieron constatar que la introducción en el motor de búsqueda de los términos que integran las marcas del titular daba lugar a enlaces patrocinados de sitios competidores. El tribunal franco falló en contra de Google por violación de derechos de marca y lo condenó a pagar los perjuicios sufridos por los demandantes. Posteriormente, Google interpuso un recurso de apelación ante el superior jerárquico y este órgano jurisdiccional determinó que Google había coadyuvado a la violación de derechos de marca, confirmando la sentencia apelada. Al igual que en el caso anterior, Google recurrió de casación y se suspendió el procedimiento de igual forma. ${ }^{26}$

El tercer caso trata sobre la marca francesa Eurochallenges. CNRRH es su titular y la registró con el objeto de ejercer la actividad de agencia matrimonial. ${ }^{27}$ En el año 2003 se pudo constatar que al ingresar la marca mencionada como término de búsqueda, daba lugar a la aparición de anuncios de la competencia bajo la rúbrica de enlaces patrocinados. Al

\footnotetext{
24. TJUE, Google France y Google (C-236/o8), apartados 28 y ss.

25. TJUE, Google France y Google (C-236/o8), apartado 33.

26. TJUE, Google France y Google (C-236/o8), apartados 36 y 37.

27. TJUE, Google France y Google (C-236/o8), apartado 38.
} 
igual que en los casos anteriores, Google fue condenado reiteradamente por los tribunales francos. ${ }^{28}$

La interpretación que realiza el Tribunal de Justicia de la Unión Europea con ánimo de determinar si se constituye uso marcario se efectúa sobre la siguiente normativa: la Directiva 89/104 artículo 5, apartado I letra a) y Reglamento 40/94 artículo 9, apartado I letra a) establecen: «el titular de la marca está facultado para prohibir a cualquier tercero el uso, sin su consentimiento, de un signo idéntico a dicha marca, cuando dicho uso se produzca en el tráfico económico, para productos o servicios idénticos a aquellos para los que la marca está registrada, y menoscabe o pueda menoscabar las funciones de la marca». ${ }^{29}$

El Tribunal de Justicia de la Unión Europea exige que el uso se efectúe en el tráfico económico, lo cual se cumple y queda bastante claro al determinar que «el uso del signo idéntico a la marca se produce en el tráfico económico si se realiza en el contexto de una actividad comercial con ánimo de lucro y no en la esfera privada» $.3^{\circ}$ Concluyendo que definitivamente en el caso de utilizar las marcas como palabras clave estamos en presencia de un uso en el tráfico económico.

Lo relatado se explica dado que la marca registrada es el medio que determina la aparición del anuncio en internet y en virtud del rol que desempeña es imposible pretender que dicho uso ocurra en un ámbito distinto del comercial. ${ }^{3 \text { I }}$ Como podrán prever, el ánimo de lucro queda de manifiesto desde que entendemos que la publicidad tiene por objeto conseguir clientes.

Recapitulando, para que el titular pueda prohibir el uso de su respectiva marca es necesario que éste se extienda en el tráfico económico. Pero, además, que dicha utilización sea para productos o servicios idénticos a aquellos para los que la marca está registrada. En principio se ha entendido que se refiere a los productos o servicios del tercero que emplea la marca. ${ }^{2}$

Por otro lado, Google ha planteado que si no se hace mención al

28. TJUE, Google France y Google (C-236/o8), apartados 36 y 37 .

29. TJUE, Google France y Google (C-236/08), apartado 49.

30. TJUE, Google France y Google (C-236/08), apartado 50.

3 I. TJUE, Google France y Google (C-236/08), apartado 52.

32. TJUE, Google France y Google (C-236/o8), apartado 60. 
signo en el propio anuncio, no puede afirmarse que exista un uso marcario para productos y servicios. Sin embargo, el tribunal estimó que la utilización de la marca como palabra clave en un motor de búsqueda sí está comprendido en el concepto de uso para productos y servicios en el sentido del artículo 5 de la Directiva $89 / \mathrm{IO}^{33}$ y conforme el reglamento que aplica a las marcas comunitarias. ${ }^{34}$

De lo anterior es relevante entender que independiente de que la marca no aparezca en el anuncio, igualmente la judicatura europea entiende que existe un uso comercial para distinguir productos y servicios.

El TJUE ha entendido que el derecho que se concede al titular para prohibir el uso de su marca está fundando en los intereses específicos que protege. Por ello, para poder prohibir el uso del signo distintivo, se deben cumplir copulativamente los requisitos anteriores en conjunto con el menoscabo a la función marcaria. ${ }^{35}$ A continuación trataremos el análisis que hizo el TJUE de las funciones de la marca, en particular la función de publicidad y la función de indicación de origen.

El tribunal indicado asegura que la función esencial de la marca «consiste en garantizar al consumidor o al usuario final la identidad de origen del producto o del servicio que con ella se designa, permitiéndole distinguir dicho producto o servicio de los que tienen otra procedencia». ${ }^{36}$

La utilización de una palabra clave, que a su vez es una marca registrada, no implica necesariamente un menoscabo a la función de origen, cuando se desprende del aviso que éste corresponde a un anunciante o a una empresa diferente del término que se ingresa. Si hay un menoscabo a esta función, dependerá de la forma en que se muestre el anuncio. Es insostenible plantear que el hecho de utilizar una palabra clave afecta la denominación de origen si el anuncio alude a una empresa no relacionada.

Absolutamente opuesto es el caso en que el propio anuncio desplegado utilice la marca ajena en el encabezado, dado que sugeriría una relación entre el anunciante y el titular de la marca. ${ }^{37}$ En dicha situación hay una manifiesta afectación de la función indicativa de origen, por

\footnotetext{
33. TJUE, Google France y Google (C-236/o8), apartado 65.

34. TJUE, Google France y Google (C-236/o8), apartados 73 y 74.

35. TJUE, Google France y Google (C-236/o8), apartado 75.

36. TJUE, Google France y Google (C-236/o8), apartado 82.

37. TJUE, Google France y Google (C-236/o8), apartado 89.
} 
cuanto los consumidores creerían que la oferta del producto proviene de una empresa cuando realmente lo ofrece otra.

Conforme el análisis del TJUE, la utilización de una marca ajena como palabra clave no produce un menoscabo a la función de publicidad, aunque se reconocen ciertas repercusiones que podrían afectar al titular. Por ejemplo, el aumento del valor del anuncio en caso de querer publicar uno propio, ya que su marca sería utilizada simultáneamente por varios anunciantes. En este caso se paga un valor por clic superior al que se pagaría si no se autorizara el uso a otros anunciantes.

Recordemos que el valor del anuncio depende de la relevancia que tiene la palabra clave, lo cual varía en virtud del tráfico que ésta genere, y simultáneamente mientras más anunciantes utilicen una palabra, mayor será el valor del anuncio. Por regla general el anuncio más costoso es el que tiene mejor ubicación al existir múltiples anunciantes. No obstante, el Tribunal concluye de forma tajante: «estas repercusiones del uso de un signo idéntico a la marca por terceros no constituyen por sí mismas un menoscabo de la función de publicidad de la marca", $3^{8}$ lo cual no nos parece evidente.

\section{La responsabilidad del anunciante}

La interpretación que realizó el TJUE respecto de la Directiva 89/104 y el Reglamento 40/94, concluyó que «el titular de una marca está facultado para prohibir a un anunciante que, a partir de una palabra clave idéntica a la marca que haya seleccionado sin consentimiento del titular en el marco de un servicio de indexación en internet, haga publicidad de productos o servicios idénticos a aquellos para los que se ha registrado la marca, cuando dicha publicidad no permite o apenas permite al internauta medio determinar si los productos o servicios incluidos en el anuncio proceden del titular de la marca o de una empresa económicamente vinculada a éste o si, por el contrario, proceden de un tercero». 39

De esta forma, una marca comunitaria puede utilizarse para desplegar anuncios en internet en el marco de un servicio de indexación, como lo es Google Adwords, toda vez que el anuncio se identifique claramente

38. TJUE, Google France y Google (C-236/08), apartado 95.

39. TJUE, Google France y Google (C-236/o8), apartados 99 y г 2 I. 
como tal y no exista duda acerca de que el anunciante es un tercero que no está relacionado con el titular de la marca.

Por lo tanto, conforme a esta jurisprudencia, no se le adjudica responsabilidad al anunciante por el mero uso de una marca ajena como palabra clave, lo que nos parece positivo al favorecer la competencia y la información entre los usuarios, pero no pondera el menoscabo a la función de la marca que pudiese ocurrir en los casos concretos.

\section{La responsabilidad del buscador}

A pesar de que el TJUE señala que se configura un uso comercial de la marca, entiende que esto no significa que el prestador del servicio de indexación haga uso de la marca por sí mismo, en conformidad con el artículo 5 de la Directiva 89/ı04 y el artículo 9 del Reglamento 40/94.

A juicio de la magistratura, el servicio de indexación permite a los usuarios la utilización de las marcas sin que el prestador del servicio haga uso de ellas. ${ }^{\circ}$ Este punto es particularmente importante en virtud de que consagra una tendencia en relación con los proveedores de contenido al entenderlos exclusivamente como intermediarios, lo cual tiene como resultado que éstos no tengan responsabilidad, aunque se acredite una infracción del anunciante al derecho de marcas o un acto de competencia desleal.

No está demás comentar que el hecho de recibir una remuneración por el servicio de anuncios no implica en ningún caso que por ello esté utilizando las marcas que utilizan los usuarios del sistema Adwords. ${ }^{4 \mathrm{I}}$

\section{EL CASO CHILENO: USO DE MARCAS AJENAS COMO PALABRA CLAVE}

En esta sección del texto procederemos a ver en detalle el caso chileno caratulado Acepta.com S.A con South Consulting y otros. Haremos una descripción de los hechos, trataremos detenidamente la demanda interpuesta y cuál fue la correspondiente contestación, para finalmente referirnos a la decisión que adoptó el juez de primera instancia con sus respectivos fundamentos.

\footnotetext{
40. TJUE, Google France y Google (C-236/o8), apartados 55 y 56.

4I. TJUE, Google France y Google (C-236/o8), apartado 57.
} 
En Chile se está llevando a cabo un juicio que involucró directamente a las empresas Google Chile Ltda y Google Inc., y se trataría del primero que conocen nuestros tribunales.

La empresa de facturación electrónica demandada, South Consulting S.A, contrató los servicios del buscador con el objeto de publicar un número indeterminado de anuncios y así promocionar su propia compañía a través de internet. Entre los hechos más relevantes se constató que al ingresar por separado cada uno de los siguientes términos: «Acepta», «Azurian», «DBNet» y «Paperless», aparecía en los resultados de búsqueda un anuncio en el cual podía leerse claramente la marca respectiva. Además al hacer clic en el anuncio, se redirige al usuario al sitio institucional de South Consulting S.A.

Debemos señalar que este litigio se ajusta al caso paradigmático del uso de marca ajena en internet en el cual se utiliza simultáneamente la marca comercial del tercero como encabezado y como palabra clave. Merece tener presente que este caso es mucho más claro en su solución que aquél en que el supuesto fáctico es distinto y la marca registrada se utiliza exclusivamente como palabra clave.

\section{LA DEMANDA}

La demanda fue interpuesta por la empresa Acepta.com S.A, prestadora de servicios de certificación; la sociedad Azurian Tecnología Limitada, quien se dedica a la implementación de tecnologías informática; la sociedad anónima DBNet Ingeniería de Software, que tiene como giro la facturación electrónica; y E-Partners S.A, que participa del mismo rubro. ${ }^{42}$

El libelo presentado interpuso las siguientes acciones fundadas en el artículo 5 de la Ley 20.169 y el artículo ro6 de la LPI:

- Acción declarativa de actos de competencia desleal y de violación a los derechos de propiedad industrial.

- Acción de cesación de actos de competencia desleal y de actos en violación de los derechos de propiedad industrial.

42. Acepta.com S.A con South Consulting y otros (2OI2), Tercer Juzgado Civil de Santiago, rol 55530-09, 28 de noviembre de 20I 2, fojas 2. 
- Adopción de medidas necesarias para evitar que prosiga la infracción a la ley de propiedad industrial.

- Acción de remoción de los efectos producidos por los actos de competencia desleal y de violación de derechos de propiedad industrial.

- Acción de indemnización de los perjuicios ocasionados por los actos de competencia desleal y de violación de derechos de propiedad industrial.

En cuanto a la fundamentación, los demandantes acuden a la definición de acto de competencia desleal consagrado en la Ley 20.169 que señala: «En general, es acto de competencia desleal toda conducta contraria a la buena fe o las buenas costumbres que, por medios ilegítimos, persiga desviar clientela de un agente del mercado».

Además, se amparan en el artículo 4 de la misma ley, citando algunos ejemplos concretos de actos de competencia desleal:

a) Toda conducta que aproveche indebidamente la reputación ajena induciendo a confundir los propios bienes, servicios, actividades, signos distintivos o establecimientos con los de un tercero. b) El uso de signos o la difusión de hechos o aseveraciones, incorrectos o falsos que induzcan a error sobre la naturaleza, proveniencia, componentes, características, precio, modo de producción, marca, idoneidad para los fines que pretende satisfacer, calidad o cantidad y, en general, sobre las ventajas realmente proporcionadas por los bienes o servicios ofrecidos, propios $\mathrm{o}$ ajenos. c) Todas las informaciones o aseveraciones incorrectas o falsas sobre los bienes, servicios, actividades, signos distintivos, establecimientos o relaciones comerciales de un tercero, que sean susceptibles de menoscabar su reputación en el mercado. ${ }^{43}$

Por último, en cuanto a los aspectos formales, el artículo 5 de la Ley 20.169 establece expresamente las acciones que proceden en contra de los actos de competencia desleal y la misma ley señala que estas acciones se tramitarán conforme el procedimiento sumario.

A propósito de la propiedad industrial, los demandantes señalan que

43. Acepta.com S.A con South Consulting (2OI2), Tercer Juzgado Civil de Santiago, rol $55530-09$, foja 5 . 
el artículo i9 se refiere a la marca comercial como «todo signo que sea susceptible de representación gráfica capaz de distinguir en el mercado productos, servicios o establecimientos industriales o comerciales» ${ }^{44} \mathrm{y}$ que el mismo artículo dispone que «tales signos pueden consistir en letras, números y otros». ${ }^{45}$ También se menciona el artículo I9 bis D de la LPI, por cuanto éste señala que:

La marca confiere a su titular el derecho exclusivo y excluyente de utilizarla en el tráfico económico en la forma que se le ha conferido y para distinguir los productos, servicios, establecimientos comerciales $\mathrm{o}$ industriales comprendidos en el registro. Por consiguiente el titular de una marca registrada podrá impedir que cualquier tercero, sin su consentimiento, utilice en el curso de las operaciones comerciales marcas idénticas o similares para productos, servicios o establecimientos comerciales o industriales que sean idénticos o similares a aquellos para los cuales se ha concedido el registro, y a condición de que el uso hecho por el tercero pueda inducir a error o confusión. Cuando el uso hecho por el tercero se refiera a una marca idéntica para los productos, servicios o establecimientos comerciales o industriales idénticos, se presumirá que existe confusión. ${ }^{46}$

Por último, los demandantes respaldan las acciones entabladas en el artículo Io6 de la LPI, que las menciona expresamente y proceden en caso de violación de dicha ley. Cabe destacar que el mismo artículo contempla la posibilidad de demandar en sede civil al infractor y conforme el artículo ro7 de dicha ley, en cuyo caso el procedimiento que corresponde es el sumario.

En virtud de lo anterior, debemos destacar que a pesar de que la demanda se funda claramente en disposiciones vigentes en nuestro ordenamiento, carece de una argumentación rigurosa que señale cómo se configura la cláusula general de competencia desleal o cómo la conducta se encuadra en los casos específicos.

Igual es el caso de la propiedad industrial, en el que se limitan a citar

44. Acepta.com S.A con South Consulting (2012), Tercer Juzgado Civil de Santiago, rol $55530-09$, fojas 5 y 6.

45. Acepta.com S.A con South Consulting (20I2), Tercera Juzgado Civil de Santiago, rol $55530-09$, foja 6 .

46. Artículo I9 bis D de la Ley 19.039 sobre Propiedad Industrial. 
disposiciones de la ley y no construyen una argumentación que señale en qué forma dichas disposiciones se transgreden. Siendo una problemática moderna, nos parece indispensable fundar la pretensión con un razonamiento jurídico que establezca claramente cómo los hechos expuestos constituyen un acto de competencia desleal o una violación a la LPI.

En cuanto a los perjuicios, los demandantes manifiestan que han sufrido daño moral al ver cómo un tercero se apropia de la reputación que con tanto esfuerzo han conseguido luego de años de inversión y trabajo. Asimismo, señalan que los actos de las demandadas han provocado un daño evidente, pero nuevamente carecen de rigurosidad para señalar los daños concretos que han sufrido. Finalmente, solicitaron cinco millones de pesos para cada demandante por concepto de lucro cesante y cinco millones de pesos por concepto de daño moral.

En nuestra opinión, la demanda es poco congruente, por cuanto no respalda correctamente lo que sostiene: no existe armonía entre el derecho invocado y los hechos que justifican su aplicación. Asimismo, se invocan leyes que se rigen por procedimientos distintos, cuestión que ha sido ampliamente debatida en España y que trataremos más adelante bajo el subtítulo «Acumulación de acciones».

Además, cabe hacer una mención al daño moral, ya que hace algunas décadas era uniforme la jurisprudencia que negaba la idea de que las personas jurídicas tuviesen un patrimonio propiamente moral (Corral, 2004), así como tampoco pueden experimentar dolor, lo que haría en principio improcedente exigir una indemnización de esa naturaleza. Sin perjuicio de lo anterior, nosotros adherimos a la postura que Corral Talciani (2004) deja entrever, al señalar que el daño moral o extrapatrimonial, en un sentido amplio, implica entenderlo más allá del dolor meramente psicológico, incorporando derechos de la personalidad, como la reputación, el crédito y la confianza comercial, los cuales son plenamente aplicables a las personas jurídicas.

Indistintamente, del análisis de la demanda entendemos que los litigantes al decir daño moral se refieren equívocamente a los perjuicios patrimoniales que ha experimentado la empresa al ver cómo un tercero ha utilizado su reputación en su desmedro lucrativo. Ésta es una situación fundamentalmente comercial, que si bien puede ser de difícil prueba, es verificable y medible con relativa certeza al establecer las variaciones que han sufrido las ventas en comparación con las cifras que se esperaban, 
considerando las condiciones del mercado y el crecimiento que había experimentado la compañía en los últimos meses. Inclusive, puede determinarse de forma exacta cuántos usuarios ingresaron al sitio web de South Consulting a través del anuncio que utilizaba como palabra clave las marcas de los demandantes.

\section{CONTESTACIÓN}

\section{South Consulting S.A.}

En primer lugar, South Consulting señala ser una empresa seria que siempre se ha desempeñado en el mercado de buena fe. Posteriormente, describe los hechos señalando que en ningún caso han intentado usar la marca de un tercero para redirigir la clientela a su sitio institucional y que lo ocurrido se debe a un error o hecho involuntario en la contratación, intermediación o prestación de los servicios de posicionamiento. Agregan que solucionaron el error en enero de 2009, al tomar conocimiento del mismo. En síntesis, destacan que no hay una intención positiva por parte de la empresa de realizar los actos que se le imputan en la demanda.

En cuanto a la defensa, basados en cuestiones formales señalan que las acciones interpuestas no se pueden interponer conjunta y simultáneamente. Lo anterior, se debe a que no existe una norma que faculte expresamente a interponer conjuntamente acciones de la ley de propiedad industrial y de competencia desleal. Posteriormente, los demandados indican que en ausencia de dicha norma, debemos acudir a las reglas generales que establecen en el inciso primero del artículo i 7 del Código de Procedimiento Civil que «pueden entablarse acciones en un mismo juicio con tal que no sean incompatibles».

De tal forma, a pesar de que ambas acciones se rigen por el procedimiento sumario, la defensa de South Consulting argumenta que son pretensiones de distinta naturaleza, que se encuentran sometidas a reglas de responsabilidad diferentes. Destacamos en particular, que existen distintas formas de apreciar la prueba, distintos requisitos para acreditar el daño y diversos bienes jurídicos protegidos, diferencias tan importantes que llevan a concluir que las acciones interpuestas son derechamente incompatibles. 
Finalmente, concluyen que al estar la demanda mal planteada se afecta el legítimo derecho a defensa, dado que:

- No queda claro conforme a qué reglas se apreciará la prueba.

- No hay certeza respecto de si procede la sustitución de procedimiento.

- Se ignora el bien jurídico que motiva las acciones y por ende se desconoce la orientación que debe adoptar la defensa.

- Se desconocen las reglas aplicables para defenderse del daño imputado en autos.

En el caso de que las acciones conjuntamente interpuestas fuesen procedentes, se solicita rechazar la demanda en todas sus partes debido a que no existe solidaridad entre South Consulting y Google.

Respecto de la acción declarativa de acto de competencia desleal, la defensa de South Consulting señala de forma manifiesta que no hay concurrencia de los supuestos legales para hacerlos responsables y sostienen que la definición de nuestro ordenamiento exige una mala fe de la cual su representada carece.

Luego, se refiere al eventual acto de confusión que a su juicio no ocurre. En el anuncio se hace una clara alusión al sitio web institucional de South Consulting, por lo cual la persona que accede a internet podría darse cuenta del error que se estaba generando.

En virtud de lo anterior, tampoco sería procedente la acción de remoción de los efectos producidos por actos de competencia desleal y la acción de indemnización de perjuicios derivada de actos de competencia desleal.

Posteriormente, respecto de la LPI, se alega la improcedencia de la acción declarativa de violación a los derechos de propiedad industrial por la falta de concurrencia de los presupuestos legales para hacer responsable a la empresa. Sus argumentos son que no está acreditado el registro de las respectivas marcas, que la utilización de la palabra clave en un motor de búsqueda no corresponde a un uso comercial y finalmente que no se acredita el elemento subjetivo de querer producir confusión en los consumidores.

Asimismo, la acción de cesación de actos de violación a los derechos de propiedad industrial no procede dado que no existe violación alguna 
y, por otro lado, la empresa removió los anuncios cuando descubrió la situación.

Finalmente, tanto la adopción de medidas destinadas a evitar la infracción de la LPI, la acción de remoción de los efectos producidos por la contravención señalada y la acción de indemnización de perjuicios no serían procedentes al no existir una violación de derechos de propiedad industrial.

\section{Google Chile Ltda.}

En la contestación, la defensa señala en primer término que niega y controvierte de manera completa y cabal todos y cada uno de los supuestos hechos que se señalan en la demanda. Asimismo, sostiene que la carga de la prueba les corresponde completamente a los demandantes.

Luego, Google Chile señala que la demanda debe ser desechada por las siguientes consideraciones:

- Las acciones de la Ley de Propiedad Industrial y las acciones de competencia desleal no pueden tramitarse en un mismo juicio sumario.

- La demanda no señala de manera clara de qué forma Google Chile habría realizado algún acto de competencia desleal o violación de derechos marcarios.

- La demanda carece de base por cuanto South Consulting no contrató con Google Chile.

- Google Chile no tiene relación alguna con el servicio Google Adwords.

Google Inc.

La empresa estadounidense arguye que el Tercer Juzgado Civil de Santiago es incompetente de conformidad con lo dispuesto en el artículo 303 núm. I del Código de Procedimiento Civil, debido a que el demandado tiene domicilio en California, Estados Unidos, y además agrega que no existe una disposición que modifique la regla general consagrada en la disposición recién citada. 
Simultáneamente, opone la excepción de ineptitud del libelo por cuanto no se señaló propiamente el domicilio de la empresa y destaca que las notificaciones anteriores quedaron nulas. Finalmente sostienen que hay falta de jurisdicción, de conformidad con el artículo 303 núm. 6 del Código de Procedimiento Civil.

En subsidio de las excepciones mencionadas, se contestó la demanda señalando que debe ser rechazada en todas sus partes, conforme los siguientes argumentos.

En primer lugar, se alegó la falta de jurisdicción del tribunal respecto de Google Inc. de conformidad con el artículo I 34 del Código Orgánico de Tribunales y teniendo presente que Google Inc. tiene su domicilio en los Estados Unidos, el tribunal carece de jurisdicción para conocer el conflicto planteado.

En segundo lugar, al igual que en la defensa de los demás demandantes, se sostiene que las acciones de la Ley de Propiedad Industrial y las acciones de la Ley de Competencia Desleal no pueden tramitarse en un mismo juicio sumario. Cabe enfatizar que existe incompatibilidad respecto de la apreciación de la prueba, diferencias en las normas relativas a la valoración de la prueba y, en particular, la LPI posee normas especiales para determinar el perjuicio y los responsables de indemnizarlo.

En tercer lugar, sostienen que las expresiones «Acepta», "Azurian», «DBNet» $\mathrm{y}$ «Paperless», no son marcas registradas de los demandantes. Lo anterior se debe a que los signos «Acepta», «Azurian», «DBNet» no están registrados como marca en Chile. Mientras «Paperless» goza de protección exclusivamente como marca mixta, dado que de forma aislada no está registrada en nuestro país.

El cuarto argumento de Google Inc. alude a un supuesto de facto. La empresa se autodenomina como una plataforma neutral, en la cual los distintos anunciantes pueden publicitar sus productos y servicios. Además agregan que el hecho de que esta situación ocurra en internet no es diferente de los avisos clasificados o las páginas amarillas en las cuales el anunciante es el único responsable del contenido de su anuncio.

Por ende, concluyen que si alguien desvió clientela de forma ilegal, en ningún caso fue Google. Asimismo, la empresa exige a todos sus anunciantes que respeten la propiedad industrial e intelectual de terceros e incluso afirma que no puede revisar a priori toda publicidad por violación de derechos de terceros o por actos de competencia desleal. 
El último argumento señala que no cumplen los requisitos copulativos necesarios para acreditar la responsabilidad extracontractual de Google. Lo anterior es evidente al considerar que no existe un hecho ilícito, que no hubo dolo o culpa en la conducta de la empresa y además no existe una relación causal entre los daños y los hechos que se imputan.

\section{SENTENCIA DE PRIMERA INSTANCIA}

El tribunal de primera instancia acogió la demanda al considerar que South Consulting cometió actos de competencia desleal, afectando los derechos de los demandantes. Además, la empresa condenada debió cesar dichos actos de competencia desleal y de violación a los derechos de propiedad industrial.

Respecto de los perjuicios demandados por concepto de lucro cesante, el magistrado desestimó su indemnización dado que no se acreditaron adecuadamente. En tanto que la compensación por concepto de daño moral no fue concedida dado que, a pesar de que se acreditó el acto de competencia desleal, no se comprobó una afectación al prestigio de la marca.

Finalmente se condenó en costas a South Consulting y se le ordenó publicar copia íntegra de la sentencia en el diario El Mercurio a sus propias expensas. Por otro lado, cabe señalar que con fecha 24 de marzo de 20I4, la Segunda Sala de la Corte de Apelaciones de Santiago confirmó la sentencia apelada en virtud de los artículos I 86 y siguientes del Código de Procedimiento Civil, sin señalar fundamento alguno. ${ }^{47}$

\section{FUNDAMENTOS DE LA DECISIÓN DEL JUEZ}

En primer término, para justificar su decisión, el tribunal primitivo pretende dilucidar si efectivamente South Consulting utilizó marcas de la competencia y si estas últimas estaban protegidas al momento de los hechos..$^{8}$

47. Acepta.com S.A con South Consulting (2013), Corte de Apelaciones de Santiago, Segunda Sala, rol 484-I3, 24 de marzo de 20 I $4^{2}$

48. Sentencia del caso Acepta.com S.A con South Consulting y otros (2012), Tercer Juzgado Civil de Santiago, rol $55530-09$, considerando quincuagésimo octavo. 
Como mencionamos anteriormente, el anunciante sostuvo que los hechos se debían a un error de sus dependientes. Sin embargo, el tribunal determinó que existe un acto voluntario en la inclusión de palabras clave. Además, dio por acreditado el uso de los nombres de las demandantes cuyas empresas constituyen competencia directa. ${ }^{49}$

Continuando con la fundamentación, el magistrado procedió a analizar si las denominaciones «Acepta», «Azurian», «DBNet»y «Paperless» se encuentran protegidas, ya que son los términos utilizados en el buscador. ${ }^{50}$ Cabe agregar que las marcas protegidas son: «Acepta.com», «Azurian», «Objetos DBNet», «DBNet, Arquitectura de Software» y «Paperless», y la protección que otorga el derecho marcario supone el conjunto y no los términos considerados de forma aislada (FernándezNovoa, 2004).

A pesar de lo anterior, el tribunal descarta la alegación respecto de que sólo se protege la marca mixta, dado que es irrelevante para la Ley 20.I69 y además la intención del anunciante fue desviar la clientela de los demandantes por medio de las denominaciones con la cual se identifican en el mercado. ${ }^{51}$ En síntesis, el magistrado acredita el uso de los signos distintivos «Acepta», «Azurian», «DBNet» y «Paperless» como palabras clave en el sistema de búsqueda de Google, además de constatar que los internautas utilizaron dichos términos y que efectivamente los vocablos empleados son marcas pertenecientes a los demandantes.

A continuación, mencionaremos los fundamentos de la decisión y la respuesta que el tribunal dio a las diversas alegaciones y defensa de Google Chile y Google Inc.

En primer lugar, el tribunal descartó que las acciones de la Ley de Propiedad Industrial y las acciones de la Ley de Competencia Desleal fuesen incompatibles, como argumentaba Google Chile. Se entiende que el actor se ha limitado a interponer las acciones que establece la Ley 20.I69, y que la LPI simplemente ha sido citada con el objeto de apoyar

49. Sentencia del caso Acepta.com S.A con South Consulting y otros (2012), Tercer Juzgado Civil de Santiago, rol $55530-09$, quincuagésimo octavo.

50. Sentencia del caso Acepta.com S.A con South Consulting y otros (2012), Tercer Juzgado Civil de Santiago, rol $55530-09$, quincuagésimo noveno.

5I. Sentencia del caso Acepta.com S.A con South Consulting y otros (2012), Tercer Juzgado Civil de Santiago, rol $55530-09$, quincuagésimo noveno. 
sus argumentos y para hacer uso de ciertas definiciones legales. A juicio del magistrado, el artículo 2 faculta al afectado por un acto de competencia desleal, para interponer las acciones que concede dicha ley aunque el mismo acto pudiese implicar una infracción a la LPI. ${ }^{52}$

Respecto del hecho de que la demandada no señala cómo se habría cometido un acto de competencia desleal, el Tercer Juzgado Civil de Santiago se limita a mencionar que el libelo dice expresamente que South Consulting contrató los servicios de Google y que pagaba un precio para que éste publicara las marcas registradas de propiedad de los demandantes.

La tercera alegación sobre la cual el tribunal se pronuncia es que Google Chile no habría contratado con el anunciante. En virtud del mérito de los antecedentes acompañados, se probó que la contratación se perfeccionó a través de la página de Google Chile, pero a juicio de la magistratura no se rindió prueba suficiente para determinar con toda claridad la vinculación existente entre ambas. ${ }^{53}$

En relación con las alegaciones efectuadas por Google Inc., el tribunal señaló que «no sólo posee jurisdicción sino que además es el órgano competente para resolver la contienda suscitada entre las partes». ${ }^{54}$ Asimismo, las demandadas sólo han ejercido las acciones contempladas en la Ley 20.I69, por lo cual no existe la falta de jurisdicción ni la supuesta incompatibilidad de procedimiento que manifestó Google Inc. en la contestación de la demanda.

Mientras Google Inc. sostenía que los términos utilizados como palabras clave carecían de protección en favor de las demandantes, el magistrado fue categórico al señalar que se contradice dicha aseveración con la prueba documental rendida en juicio.

Respecto del procedimiento de reclamo que existe en el sistema Adwords y en el cual se ampara Google Inc. para sostener su calidad de mero intermediario que no tiene responsabilidad en las publicaciones

52. Sentencia del caso Acepta.com S.A con South Consulting y otros (2012), Tercer Juzgado Civil de Santiago, rol $55530-09$, quincuagésimo séptimo.

53. Sentencia del caso Acepta.com S.A con South Consulting y otros (2012), Tercer Juzgado Civil de Santiago, rol $55530-09$, sexagésimo primero.

54. Sentencia del caso Acepta.com S.A con South Consulting y otros (2012), Tercer Juzgado Civil de Santiago, rol $55530-09$, sexagésimo segundo. 
que emiten los anunciantes, el Tercer Juzgado Civil de Santiago es tajante al señalar que a pesar de que existe dicho mecanismo, éste no es idóneo puesto que se desechó la denuncia realizada por la utilización de Acepta.com sin mayor análisis, exclusivamente debido a que es una marca mixta.

Finalmente, el tribunal acogió la argumentación conforme a la cual Google Inc. no es responsable de los actos de competencia desleal, por no tener una participación directa y en virtud de que no se cumplen los requisitos para acreditar la existencia de responsabilidad civil.

Cabe destacar que el Tercer Juzgado Civil de Santiago entiende que Google Inc. se limita a poner a disposición de los usuarios un medio de comunicación masivo, sin ser responsable de los contenidos de las publicaciones. Además, siendo tal la cantidad de marcas que gozan de protección, no es factible pretender que la empresa tome conocimiento de cada una de ellas.

En relación con los fundamentos del Tercer Juzgado Civil de Santiago para adjudicar responsabilidad a South Consulting, estableció que incorporar marcas como palabras clave implica necesariamente un acto voluntario. Posteriormente, se analiza la defensa que sostiene la improcedencia de la acción declarativa de acto de competencia desleal por no haberse incurrido en un acto de dicha naturaleza. Lo anterior se descarta dado que consta en autos que se utilizó las marcas de la competencia como palabra clave en la publicidad de Google, lo cual constituye un acto de competencia desleal a juicio de la judicatura. Además, se configura el elemento subjetivo propio de la conducta que tiene por propósito desviar clientela, lo cual lleva a la inevitable conclusión de que se generó confusión en los usuarios.

Finalmente el tribunal descartó la alegación de improcedencia de las demás acciones, dado que se acreditó definitivamente la intencionalidad de South Consulting al momento de incorporar la publicidad.

\section{CUESTIONES DOGMÁTICAS A DESTACAR}

\section{Acumulación de acciones}

Es crucial para la práctica y el entendimiento del derecho de la competencia desleal, ver cómo se relaciona con la propiedad intelectual, más 
aún en estos supuestos en los que tratamos una materia que afecta directamente marcas comerciales. Debemos adherir a una relación que dé armonía y sentido al sistema, evitando entender ambas materias en una relación de "generalidad-especialidad estricta» (Massaguer, 20 I I: 22) o «una relación de acumulación indiscriminada» (Massaguer, 20II: 22). Es menester evitar concepciones erróneas que no dan un real sentido al ordenamiento jurídico, ya sea por dar primacía absoluta a una ley por sobre otra o por otorgar una protección doble que carece de sentido.

Como antecedente previo para entender qué tipo de relación existe entre el derecho de marcas y la competencia desleal, es pertinente comentar la doctrina tradicional española. Anteriormente la doctrina española sostenía la tesis de la primacía, la cual plantea que la ley de marcas es especial en la materia, debiendo aplicarse por sobre la ley de competencia desleal y quedando esta última relegada a una aplicación excepcionalísima, en casos en que los flancos sin protección fuesen tan burdos en la normativa especial que impidieran un mercado transparente, justificando así la aplicación de la ley general (García Pérez, 20 I I).

Dado que «la jurisprudencia ha rechazado de plano la solución simplista basada en un formal principio de especialidad legislativa» (Massaguer, 20I I: 22), se han buscado nuevas soluciones, lo que constituye una forma distinta de entender la aplicación de ambas leyes. Esto se debe en gran parte a que el derecho de la Unión Europea ha hecho incompatible mantener la tesis de la primacía del derecho de marcas sobre el régimen de competencia desleal (García Pérez, 20II). Entonces, ha surgido la "complementariedad relativa» (Massaguer, 20II: 22) para entender la relación que existe entre el derecho de marcas y la competencia desleal, dejando de lado la aplicación estricta basada en la especialidad y dando lugar a criterios rectores que permiten completar la protección que otorgan los sistemas de propiedad industrial.

Cabe destacar que actualmente la complementariedad relativa es la doctrina que ha tomado más fuerza en la nueva práctica judicial española. Adherimos a ella para el caso chileno por su cercanía y similitud con nuestra legislatura..$^{55}$

55. Como ya señalábamos, sostenemos que ciertamente existe uniformidad en la doctrina española al entender la relación de la competencia desleal y el derecho marcario, lo cual destacamos debido a que sigue siendo la visión imperante en las más recientes 
A continuación mencionamos los criterios rectores que establece Massaguer (20II) para la aplicación complementaria de la ley de competencia desleal en el caso español. En primer lugar, no corresponde aplicarla para combatir conductas que quedan plenamente comprendidas en la esfera de protección de la propiedad intelectual (Massaguer, 20II). Para utilizarla en los casos relacionados con la explotación de un signo distintivo que está protegido por la propiedad intelectual, o es susceptible de ser protegido, se requiere necesariamente que la protección no se encuentre vigente o no exista un derecho de esta clase (en caso contrario, la situación quedaría plenamente cubierta por el derecho de marcas).

En cambio, si estuviese vigente o existiese el derecho, la conducta que se pretende sancionar de forma complementaria debe presentar «una dimensión anticoncurrencial específica, distinta de aquella que es común con los criterios que determinan la ilicitud de la invasión de la esfera de exclusividad que atribuye el derecho de propiedad industrial a su titular» (Massaguer, 20II: 23).

En segundo término, se debe exigir que la conducta considerada para la aplicación de la Ley de Competencia Desleal cumpla cabalmente las normas y principios propios de la regulación de la materia. En este caso, para ejercer una aplicación complementaria de la legislación de la competencia será necesario que los «remedios» no impliquen una contradicción en el ordenamiento, como lo sería proteger signos cuya protección está expresamente prohibida por la LPI.

Asimismo, complementando la visión de los autores nos parece de vital importancia entender los distintos cuerpos legislativos que protegen el mercado y la relación entre los mismos como un todo en el que las diferentes normas no son elementos ajenos entre sí.

Debemos entender las disposiciones que tutelan los derechos subjetivos de los titulares de las marcas y los cuerpos normativos que velan por los presupuestos del sistema, no como un conjunto que se relaciona de forma simplista al seguir la teoría de la primacía, ni tampoco como cuerpos normativos que deben ser aplicados indiscriminadamente, sino como un conjunto de disposiciones que se relaciona y compone un sistema jurídico.

publicaciones en la materia. Para revisar el tratamiento que se realiza de esta cuestión en España en una publicación reciente, es posible acudir al libro El derecho de la competencia, comercio electrónico y marcas (20I4) de César Giner Parreño. 
Finalmente, entender las leyes como un universo de entes ajenos e independientes que no guardan relación es definitivamente una visión errónea por privarlas de sentido y no interpretarlas como un sistema que obra de forma conjunta y coherente.

\section{Presupuestos para la protección en virtud del artículo 4 letra a) de la Ley 20.169}

En primer lugar, debemos señalar que procederemos a realizar un análisis de conformidad con la legislación chilena, para determinar si el mero uso de una marca comercial como palabra clave en internet constituye un ilícito desleal.

Lo anterior, lo expondremos a propósito del estudio de la Ley 20.I69, contando con el apoyo de la doctrina que ha dado tratamiento al tema. A continuación examinamos en detalle si se configura el tipo establecido en artículo 4 letra a) de la Ley 20.I69.

El artículo 4 de la Ley 20.I69 establece lo siguiente: «En particular, y sin que la enumeración sea taxativa, se considerarán actos de competencia desleal los siguientes: a) Toda conducta que aproveche indebidamente la reputación ajena, induciendo a confundir los propios bienes, servicios, actividades, signos distintivos o establecimientos con los de un tercero». En atención a la disposición recién señalada, procederemos a examinar los diferentes elementos típicos de este acto de competencia desleal, para determinar si el uso de una marca ajena como palabra clave configura dicho ilícito.

\section{Conducta idónea para confundir a los consumidores}

Dentro de los elementos que integran el tipo, se requiere una conducta que se enmarca «en los actos de explotaciones desleal de esfuerzos ajenos, afectando tanto a la función distintiva como a la promocional de la empresa» (Contreras Blanco, 20I 2: I06). Al referirse a «toda conducta», entendemos que puede ser cualquier comportamiento o acción idónea para provocar confusión en el consumidor, incorporando toda acción que se lleve a cabo en el mercado.

Por lo expuesto, este requisito permite la inclusión de nuevos tipos de conducta que, por ejemplo, no eran conocidos al momento de la crea- 
ción de la norma, como lo es la publicación de anuncios en motores de búsqueda, utilizando signos distintivos como palabras clave.

En síntesis, podemos asegurar que es irrelevante el soporte mediante el cual se realiza la acción: podría ser mediante publicidad convencional o un anuncio en internet. En definitiva, no hay limitaciones en relación al medio que se utiliza para generar confusión.

\section{APROVECHAMIENTO INDEBIDO DE LA REPUTACIÓN AJENA}

En segundo lugar, el tipo exige necesariamente el beneficio indebido de la reputación ajena. Este requisito se materializa en el requerimiento de un cierto renombre. En efecto, debe existir una reputación susceptible de ser apropiada y dicho aprovechamiento «debe llevar un grado de equivocación o error suficiente como para poder usufructuar y sustraer los méritos y prestaciones empresariales de otro competidor» (Contreras Blanco, 201 2: 107).

De conformidad a lo que consta en el expediente, se trata de empresas que gozan de cierto renombre dentro del mercado, ya que llevan varios años desempeñándose en el rubro y en internet. Asimismo, la doctrina nacional considera que estos signos son susceptibles de protección, por cuanto es un derecho autónomo que no se limita por la normativa de propiedad industrial, ni por sus registros (Contreras Blanco, 20I2).

En particular, como requisito del tipo, el objeto sobre el cual se pretende generar confusión debe ser capaz de atraer clientela por sí mismo. En el caso chileno, las marcas pendientes de registro sí tienen la capacidad para atraer clientes ya que, como comentábamos, son conocidas por el público.

En conjunto con lo anterior se debe probar la reputación, lo cual se logra si el signo está implantado en el mercado o es conocido por el círculo de destinatarios. Esto se acredita en autos, ya que existe una página web y ésta ocupa los primeros lugares dentro de los resultados naturales.

Finalmente, para satisfacer este segundo requisito del tipo, debe existir un aprovechamiento de carácter indebido, ya que en caso contrario la conducta no se reputa desleal. En nuestra opinión, el uso de marcas ajenas como palabras clave es el tipo de conducta desleal que pretende evitar la Ley 20.169, porque más allá de las formas, el fondo de la conducta implica aprovecharse del trabajo ajeno, en menoscabo del tercero y sin que exista un vínculo comercial que lo justifique (Massaguer, I999). 
En síntesis, este requisito se satisface, por lo cual concluimos que la utilización de estas marcas como palabra clave en el contexto señalado implica un aprovechamiento indebido de la reputación ajena.

\section{EL RIESGO DE CONFUSIÓN}

En tercer lugar, el tipo requiere el riesgo de confusión. Este puede ser directo cuando los consumidores no pueden diferenciar que los bienes, servicios o los establecimientos de una empresa corresponden a otra (Rivas Sánchez, 20I2). También puede ser indirecto, situación presente cuando los consumidores sí pueden diferenciar claramente bienes, servicios o establecimientos, pero pueden pensar que corresponden a una misma empresa (Contreras, 20I2). Finalmente, podría ser una confusión en modalidad de riesgo de asociación, lo cual ocurre cuando el consumidor cree que en virtud de ciertas similitudes existentes entre algunos elementos que caracterizan la oferta de ambas, hay una vinculación económica u organizativa, cuando en realidad dicho vínculo no existe (Massaguer, 2OII).

Luego de saber cómo funciona el sistema de Adwords y tras ver los avances que han efectuado para distinguir los anuncios de los resultados naturales, no podemos afirmar que publicar un aviso que sólo utilice una marca ajena para desplegarse genere un riesgo de confusión como los señalados precedentemente, pues estos avisos publicitarios, que fueron intensamente problemáticos en jurisprudencia comparada y respecto de los cuales se señaló que podían confundir efectivamente a los usuarios, actualmente tienen una etiqueta que indica «Anuncio» y que los distingue completamente de los resultados de búsqueda.

No obstante lo anterior, ciertamente existirá confusión en el caso de utilizar el signo como palabra clave y simultáneamente como encabezado o título del anuncio. Dicha situación favorece la confusión, por cuanto al utilizar la marca visualmente, el usuario realmente cree que ingresa al sitio web del respectivo titular, cuando en realidad dicha situación no es efectiva. Por otro lado, redirigir a un usuario al sitio web propio por medio de un signo distintivo o marca ajena, perteneciente a un competidor, implica necesariamente que se está utilizando la reputación de un tercero como lo exige nuestra Ley de Competencia Desleal.

Finalmente, la marca como encabezado podría generar, dependiendo 
de los matices fácticos, una confusión directa, indirecta o en modalidad de riesgo de asociación, dependiendo también del usuario, su conocimiento y su conciencia acerca de estas prácticas publicitarias.

Particularmente en el caso chileno, que utiliza la marca como encabezado y palabra clave, parece más probable una confusión en modalidad de asociación, ya que el encabezado del anuncio induce a pensar que entre el anunciante y el titular de la marca hay sin duda algún vínculo organizativo o económico. Además de que en el contenido del aviso aparece el sitio web de otra empresa del rubro de la facturación electrónica, que impide o hace más difícil que ocurra una confusión directa.

Así, con el objeto de tener mayor claridad, la figura 5 muestra el anuncio que aparecía al ingresar el signo distintivo «Paperless» en la barra de búsqueda.

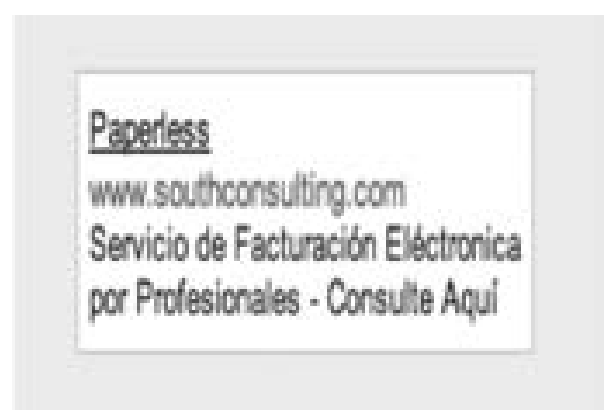

Figura 5.

\section{EL OBJETO DE LA CONFUSIÓN}

Respecto del último requisito del tipo, la confusión debe recaer sobre «bienes, servicios, actividades, signos distintivos o establecimientos». En el caso que la confusión sea sobre bienes y servicios, no se configura el tipo ya que nuestro sistema pretende promover la competencia de dichas prestaciones. En el caso Google Chile, la confusión recae sobre el signo distintivo, que es ajeno al producto o servicio que se pretende distinguir, por lo cual concluimos que sí se cumple cabalmente este requisito del tipo. 


\section{CONCLUSIÓN SOBRE LOS ACTOS DE CONFUSIÓN}

Finalmente, al apreciar que todos los elementos se satisfacen en el caso de los anuncios que utilizan los signos distintivos de los demandantes como palabra clave y encabezado, podemos decir respecto del caso chileno que los demandados configuran el ilícito del artículo 4 letra a) de la Ley de Competencia Desleal.

Además, queremos destacar que no sólo un anuncio que utiliza una marca ajena como palabra clave y encabezado constituye un ilícito desleal. También podría serlo un anuncio que sin utilizar la marca como encabezado, confunde al consumidor a través de la descripción, enlace o incluso a través del contenido del sitio web, de conformidad con la Ley 20.169.

Por último, debemos reiterar la idea anterior a través de la siguiente cita que señala: «el mero uso de palabras en el contenido de la página, que sin emplear directamente un signo protegido, hacen suponer que la página tiene alguna relación con otra empresa o con otro signo conocido...» (Heredia Sánchez, 2005: 2I). Lo anterior es plenamente aplicable en nuestro ordenamiento respecto de los actos de confusión, ya que ésta puede ser provocada a través de diversos medios presentes en un anuncio y/o en un sitio web. De tal forma, debe analizarse el contenido del anuncio y su contexto, para determinar si existe un aprovechamiento del esfuerzo ajeno.

\section{PROTECCIÓN DE MARCAS NO REGISTRADAS}

Luego de determinar en qué caso se configura el ilícito consagrado en la Ley de Competencia Desleal, procederemos a tratar si los signos distintivos que carecen de registro gozan de protección conforme nuestra Ley de Competencia Desleal.

Como ya anticipábamos, no es relevante si la infracción se comete a través de una marca registrada o un signo distintivo, ya que respecto de los actos de confusión la Ley 20.I69 establece como acción relevante: «Toda conducta que aproveche indebidamente la reputación ajena, induciendo a confundir los propios bienes, servicios, actividades, signos distintos o establecimientos con los de un tercero". De lo anterior se desprende que no es necesario ser el titular de una marca registrada para 
obtener protección a través de dicha ley. En definitiva, cualquier aprovechamiento de un signo distintivo que cumpla con la tipicidad de los actos de confusión debería ser sancionado.

Finalmente, cabe destacar que el derecho de la competencia desleal se satisface desde una perspectiva de acumulación de acciones (García Pérez, 20I2): utilizar signos distintivos ajenos como palabra clave justifica plenamente la aplicación de la Ley 20.I69, precisamente en virtud de que el derecho marcario no es aplicable meramente por una cuestión formal, y la aplicación complementaria no implica una incompatibilidad o contravención directa al derecho de marcas.

\section{CRÍTICAS A LA DECISIÓN DEL JUEZ}

En relación a la decisión del Tercer Juzgado Civil de Santiago, debemos ser categóricos en decir que es correcta sólo en la forma. El tribunal no hace distinciones que son cruciales para entender la cuestión y su argumentación deja entrever que la utilización de marcas comerciales como palabras clave es per se un acto de competencia desleal, siendo que ello no es efectivo conforme hemos podido apreciar en este trabajo.

La licitud de un anuncio que utiliza marcas comerciales como palabras clave es contingente: dependerá de las circunstancias específicas. Puede constituir un acto de competencia desleal siempre que provoque confusión o engaño en el consumidor, lo cual no ocurre con un anuncio que se identifica como tal y/o no utiliza la marca ajena como encabezado. Particularmente, en este caso la utilización de marcas comerciales como palabra clave, en conjunto con la utilización de dichos términos como parte del encabezado, configuran un acto de competencia desleal y simultáneamente constituyen un uso de aquellos que el titular de una marca puede prohibir conforme el artículo 52 de la LPI.

Finalmente, la sentencia no considera, al igual que la jurisprudencia extranjera, el rol de Google, que dejó de ser un intermediario desde el momento en que sugiere activamente marcas comerciales como palabras clave. Eventualmente, la empresa desconoce que son marcas comerciales, pero al poseer un rol activo no puede ampararse en la justificación clásica de los proveedores, que sostienen ser meros intermediarios y que, por ende, no son responsables por el contenido que suben sus clientes.

Al menos a la luz de esta investigación, reiteramos que no nos parece 
posible mantener el argumento cuando es el sitio de Google el que muestra las palabras clave en virtud de la relevancia y tráfico que tienen para los potenciales clientes, sin discriminar si son marcas protegidas o signos distintivos de terceros.

\section{CONCLUSIONES}

I. Google Adwords es un popular sistema de anuncios desarrollado por el famoso buscador del mismo nombre. Su uso permite desplegar anuncios mediante cualquier palabra clave libremente elegida por el anunciante, a través de lo cual puede configurarse un acto de competencia desleal, ya que en determinados supuestos la utilización de signos distintivos ajenos daría origen a confusión directa, indirecta o en modalidad de asociación, y, por ende, al aprovechamiento de la reputación ajena, lo que configuraría el ilícito desleal. Nuestra postura sostiene que el mero uso de marcas o signos distintivos ajenos como palabra clave no constituye per se un acto de competencia desleal y especialmente no configura el tipo del artículo 4 letra a) de la Ley 20.169. Lo anterior, derivado de que actualmente dichos anuncios se identifican claramente como publicidad y no utilizan visiblemente el signo distintivo o marca comercial ajena, lo que impide derechamente que exista confusión en los usuarios. En mérito de lo expuesto, no es posible sostener que el acto descrito implica el aprovechamiento ilícito de la reputación ajena, que sanciona nuestro ordenamiento.

2. El primer caso judicial chileno sobre la materia examinó la utilización de marcas comerciales y signos distintivos como palabra clave y simultáneamente como parte del encabezado del anuncio, concluyendo que dicho uso constituye un acto de competencia desleal al configurar un acto de confusión, según nuestra opinión en modalidad de riesgo de asociación. El uso al que hace referencia la sentencia constituye un acto de confusión conforme a la Ley de Competencia Desleal, debido a que el uso de los signos distintivos ocurre como palabra clave y simultáneamente como parte del contenido del anuncio, lo cual provoca una manifiesta confusión en los usuarios, que observan en un aviso publicitario que un anun- 
ciante se identifica con la marca comercial o signo distintivo que el cibernauta ingresó en la barra de búsqueda. Lo anterior configura cada uno de los elementos del tipo del artículo 4 letra a) de la Ley 20.169.

3. Cabe destacar que la aplicación del derecho es correcta en la sentencia, aunque el tribunal no tenga total claridad de las consideraciones relevantes para dar solución al caso. El tribunal de primera instancia incurre en un grave error en sus considerandos, ya que señala que el uso de una marca ajena o signo distintivo como palabra clave implica confusión en los usuarios, sin distinguir ni hacer alusión a que, en el caso examinado, ésta ocurre exclusivamente debido a que la palabra clave es también el encabezado del anuncio. En caso contrario, el cibernauta entenderá que está frente a un aviso publicado por un anunciante que utiliza sus propios signos distintivos para identificarse, y el cual es ajeno e independiente de la palabra clave ingresada para dar curso a la búsqueda. De tal forma, la postura de nuestra judicatura debiese ser que el mero uso de una marca o signo ajeno como palabra clave no constituye un ilícito desleal. Por último, en relación a la responsabilidad de Google, si el mero uso de una marca ajena como palabra clave no constituye un ilícito, menos podría serlo una sugerencia de utilización. Incluso si la marca se utilizara como encabezado y generara confusión, el buscador estaría exento de responsabilidad ya que no tiene participación alguna en la elección del encabezado o contenido del anuncio.

4. Por otro lado, consideramos que cualquier anuncio publicitario que use una marca o signo distintivo ajeno como palabra clave para desplegarse, y simultáneamente utilice el término respectivo como parte del contenido del anuncio, tendrá el mérito suficiente para confundir al usuario. Es innegable que la utilización visible de la marca hará creer a la mayoría de los consumidores que es el titular legítimo quien dispone de ella en internet, aunque dicha usanza no haya sido efectuada por el propietario respectivo. Asimismo, cabe destacar que hay muchos usos atípicos y análogos en los que el presente trabajo podría aplicarse. Actualmente Youtube despliega anuncios de la misma manera que Google. Las platafor- 
mas de descarga de aplicaciones funcionan con el mismo sistema de palabras clave. A modo de ejemplo, podemos comentar que App Store y Google Play permiten la ocurrencia de actos de competencia desleal como el comentado en este trabajo.

5. Finalmente, a través de la presente investigación hemos podido constatar que el mero uso de marcas comerciales ajenas como palabras clave no constituye un ilícito a la luz de la Ley de Competencia Desleal, y que inclusive mejora la información en el mercado, aumentando la competencia y favoreciendo a los consumidores, por cuanto mediante una marca concreta los usuarios pueden tener acceso a una mayor oferta en internet.

\section{REFERENCIAS}

BARRET, Margreth (2006). "Internet trademark suits and the demise of trademark use». U.C Davis Law Review, 39: 37I-457.

Contreras Blanco, Óscar (2OI 2). La competencia desleal y el deber de corrección en la ley chilena. Santiago: Ediciones UC.

Corral Talciani, Hernán (2004). Lecciones sobre responsabilidad civil extracontractual. Segunda edición. Santiago: Jurídica.

Fernández-Novoa, Carlos (2004). Tratado sobre derecho de marcas. Segunda edición. Madrid: Marcial Pons.

GARcía Pérez, Rafael (20I I). «Ejercicio acumulado de acciones basadas en la Ley de Marcas y en la Ley de Competencia Desleal». Congreso Gallego de Derecho Procesal. Disponible en <http://bit.ly/1KoSkxQ>.

García Pérez, Rafael (2OI2). «Nuevas relaciones entre la Ley de Marcas y la Ley de Competencia Desleal». Aranzadi Civil-mercantil, 2 (I): 25-40.

Giner Parreño, César A. (20I4). El derecho de la competencia, comercio electrónico y marcas. Valencia: Tirant lo Blanch.

Heredia SÁnchez, Lerdys Saray (2005). «La protección de los signos distintivos en la sociedad de la información. Actos de usurpación, competencia desleal y publicidad ilícita en la red. Biblioteca del Congreso Nacional de Chile». Biblioteca del Congreso Nacional de Chile. Disponible en <http://bit.ly/1IjiWfL>.

Hilliard, David, Joseph Welch y Uli Widmaier (2008). Trademarks and unfair competition. Séptima edición. Chicago: LexisNexis. 
Jacoby, Jacob y Mark SABLEman (2007). «Keyword-based advertising: filling in factual voids (Geico v. Google)». The Trademark Reporter, 3 (97): 68I-75 I.

Lastowka, Gregory (2008). «Google’s law». Brooklyn Law Review, 73: I327-I 4IO.

Massaguer, José (I999). Comentario a la Ley de Competencia Desleal. Madrid: Civitas.

-. (20II). "Competencia desleal y propiedad industrial e intelectual». Revista Otrosí (Ilustre Colegio de Abogados de Madrid), 7: 20-28. Rivas Sánchez, María (2012). Los ilícitos de competencia desleal en la jurisprudencia Chilena. Santiago: LegalPublishing.

Sharples, Andrew (2009). «Keywords, search engines and the potential for trade mark infringement». Journal of Intellectual Property Law or Practice, 4 (9): 6I4-6I6.

\section{SOBRE EL AUTOR}

Felipe Hermosilla Torres es abogado. Licenciado en Ciencias Jurídicas y Sociales de la Universidad Adolfo Ibáñez y magíster en Derecho, con mención en Derecho Privado por la misma universidad. Su correo electrónico es <afhermosilla@uc.cl>. Su dirección postal es Av. Los Militares 5885, piso 4, Las Condes, Región Metropolitana.

Este trabajo fue recibido el 25 de mayo de 20 I 5 y aprobado el I 5 de junio de 2015 . 